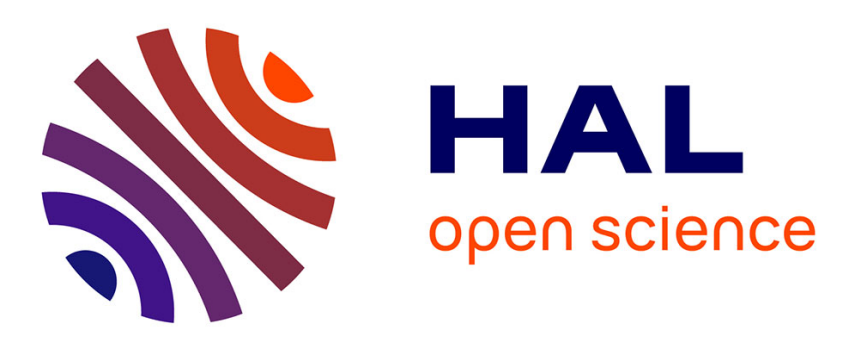

\title{
Discrete Impact Modeling of Inter- and Intra-laminar Failure in Composites
}

\author{
Christophe Bouvet, Natthawat Hongkarnjanakul, Samuel Rivallant, \\ Jean-Jacques Barrau
}

\section{- To cite this version:}

Christophe Bouvet, Natthawat Hongkarnjanakul, Samuel Rivallant, Jean-Jacques Barrau. Discrete Impact Modeling of Inter- and Intra-laminar Failure in Composites. Dynamic Failure of Composite and Sandwich Structures, 192, 2013, Solid Mechanics and Its Applications, 978-94-007-5329-7. 10.1007/978-94-007-5329-7_8 . hal-01654434

\section{HAL Id: hal-01654434 https://hal.science/hal-01654434}

Submitted on 4 Dec 2017

HAL is a multi-disciplinary open access archive for the deposit and dissemination of scientific research documents, whether they are published or not. The documents may come from teaching and research institutions in France or abroad, or from public or private research centers.
L'archive ouverte pluridisciplinaire HAL, est destinée au dépôt et à la diffusion de documents scientifiques de niveau recherche, publiés ou non, émanant des établissements d'enseignement et de recherche français ou étrangers, des laboratoires publics ou privés. 


\title{
Discrete Impact Modeling of Inter- and Intra-laminar Failure in Composites
}

\author{
Christophe Bouvet, Natthawat Hongkarnjanakul, Samuel Rivallant, \\ and Jean-Jacques Barrau
}

\begin{abstract}
The goal of this study is to initiate a "test-calculation dialogue" on low velocity/low energy impact tests in laminated composites. The different types of impact damage developing during an impact test, i.e. matrix cracking, fiber failure, interface delamination and permanent indentation, are simulated. The bibliography shows a general lack of detailed validation of impact modeling and the originality of this work is to use refined and complementary experimental data to build and validate a numerical model. The good correlation between the model and this refined experimental database gave us relative confidence in the model, despite a few nonstandard material parameters.

Permanent indentation was particularly focused and studied. Then we propose an original scenario to create permanent indentation, with a debris blocking phenomenon in the matrix cracks, as well as the corresponding model. The fiber failure model was set up using an original formulation between the integration points of the volume element in order to dissipate a constant energy release rate per unit area. Finally the model was used to evaluate the distribution of the dissipated energy among the different damage types, and demonstrated an interesting distribution between fiber failure and delamination.
\end{abstract}

\section{Introduction}

Composite materials have been increasingly used in airframe and space applications in recent decades because of their advantageous characteristics, such as their low specific weight, enhanced mechanical strength, and high stiffness coefficient.

C. Bouvet $(\varangle) \bullet$ N. Hongkarnjanakul $\bullet$ S. Rivallant $\bullet$ J.-J. Barrau INSA; UPS; Mines Albi; ISAE; ICA (Institut Clément Ader), Université de Toulouse, ISAE, 10, avenue Edouard Belin, 31055 Toulouse Cedex 4, France e-mail: christophe.bouvet@isae.fr 
Nevertheless, during the structure's life, damage induced in these materials by impacts of minor and major objects, such as hail stones, runway debris or dropped tools, can drastically decrease the structure's life.

Low velocity impact is one of the most critical load factors for composite laminates. Indeed, for structures submitted to low energy impacts or small dropped objects drops, such as tools during assembly or maintenance operations, composite laminates reveal a brittle behavior and can undergo significant damage in terms of matrix cracks, fiber breakage or delamination. This damage is particularly dangerous because it drastically reduces the residual mechanical characteristics of the structure, and at the same time can leave very limited visible marks on the impacted surface [1].

This topic has been studied extensively in recent decades, but despite the large number of studies on composite impact, both experimentally $[1-4 \ldots]$ and numerically $[5-8 \ldots]$, a general lack of detailed validation of impact modeling exists in the literature. Currently the force-displacement curve, measured during impact, and the total delaminated area, measured by ultrasonic investigation, are correlated with numerical results. Nevertheless existing ultrasonic studies do not give accurate enough results to be able to observe the separation of each delaminated interface within the plate thickness. Therefore it is often difficult to evaluate the accuracy of the proposed models due to the lack of refined experimental data to compare them with.

This paper deals with the low velocity impact study on composite laminate, both experimentally, and numerically; although this paper is more particularly focused on modeling, an important experimental data base is used, on the one hand to verify this model on different impact conditions, on the other hand to build this model. This last point encompasses the originality of this work: using a large, refined experimental database on low velocity impact on composite laminate in order to build the proposed numerical model and in particular to choose the most appropriate way to simulate each observed damage type. Consequently some modeling types chosen in this paper are taken from conventional literature; for example the interfaces to simulate delamination damage, while we performed others ourselves, such as the "plastic-like" behavior of interfaces to simulate permanent indentation. This wellknown approach can be summarized by the term "test-calculation dialogue" [9]. It enables us to better understand the experimental observations.

From an experimental view point, refined experimental investigations performed in the context of this paper, enabled us to accurately determine the different impact damage types. Conventional $\mathrm{C}$-scans enabled us to determine delaminated interfaces; but in this study a particular choice of the stacking sequence and the performance of ultrasonic examination of impacted and non-impacted plate sides, led to a precise definition of each delaminated interface (Fig. 20a). This examination was also performed at different levels of impact energy, in order to evaluate the scenario of delamination formation (Fig. 27). The conventional image correlation enabled us to determine permanent indentation; but in this study the performance of this examination on impacted and non-impacted plate sides led to a precise definition of the plate deformation after impact (Fig. 19). Micrographic cuts were 
performed in different planes, and after embedding the plate in resin, in order to precisely evaluate the impact damage and the phenomena responsible for permanent indentation (Fig. 12). This database of impact tests could enable other authors to evaluate and to improve their modeling on a well-documented case.

From the numerical viewpoint, a model was built in parallel with this experimental investigation to simulate as well as possible each observed damage type, i.e. matrix cracking, fiber failure and interface delamination. The inter-laminar damage, i.e. interface delamination, is conventionally simulated using interface elements based on fracture mechanics. Intra-laminar damage, such as matrix cracks, is conventionally simulated using interface elements based on failure criterion, but this failure criterion is not conventionally calculated: rather, it is measured in the neighboring volume elements to avoid stress concentrations. Theses interfaces also make it possible to simulate permanent indentation during impact unloading with nonconventional "plastic-like" behavior. And the fiber failure is simulated using conventional continuum damage mechanics, but with original formulation between the integration points of the element to dissipate a constant energy release rate per unit area. Then the model is used to study the effects of impact conditions, such as impact energy, boundary conditions, stacking sequence and impact velocity.

\section{Bibliography and Outline}

\subsection{Permanent Indentation and Damage Tolerance Concept}

The damage tolerance concept [10] was introduced in the seventies for civil aircraft structures and these requirements are expressed by the European certification JAR 25.571: "the damage tolerance evaluation of the structure is intended to ensure that should serious fatigue, corrosion or accidental damage occur within the operational life of the airplane, the remaining structure can withstand reasonable loads without failure or excessive structural deformation until the damage is detected". In the field of aeronautics, damage tolerance, for damage corresponding to impact loading, leads to dimensioning the structure according to impact detectability (Fig. 1): if the damage is not visibly detectable, i.e. when the impact indentation is less than barely visible impact damage (BVID), the structure must support the extreme loads and if the damage is detectable, i.e. when the impact indentation is bigger than BVID, another criterion must be considered, such as repair or change of the structure [11].

The BVID is defined as the minimum damage that can be detected by visual evaluation $[1,10]$. In the field of aeronautics, it has been demonstrated that a permanent indentation between 0.25 and $0.5 \mathrm{~mm}$ is detectable during detailed visual inspection with a probability greater than $99 \%$ [12].

This concept of impact damage tolerance induces a very special design philosophy: the residual strength of the structure after impact depends on the impact damage [10] with the conventional conclusion that the greater the impact energy, 

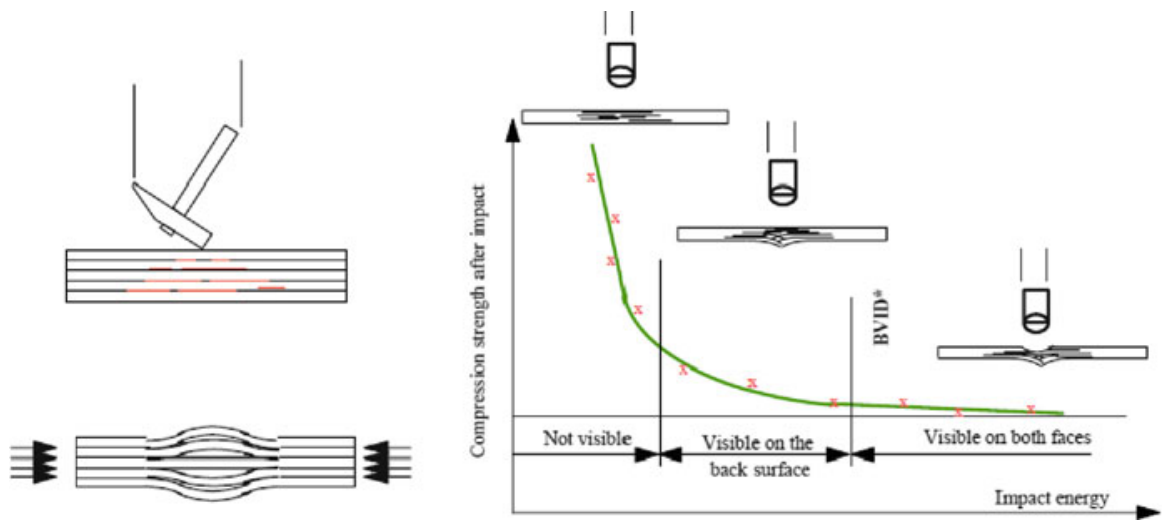

Fig. 1 Concept of impact damage tolerance: development of compression after impact, versus impact energy [10]

the greater the impact damage and consequently, the lower the residual strength. Therefore, if impact energy is known, the composite structure design is relatively conventional and the residual strength after impact should be greater than the required loads. This is for example the case for some aircraft locations where the impact energy is well known, due to statistical damage considerations. But in general, the impact energy is not known and is defined using the detectability concept. This detectability criterion makes it possible to define the BVID impact energy which is defined as the necessary impact energy to obtain a permanent indentation equal to BVID, although maximum impact energy (cut-off energy) is used to test each zone of the aircraft: consequently impact energy must not attain unreasonable values. Moreover, conventionally this BVID impact energy depends on the structure, such as material, stacking sequence, thickness, boundary conditions, or location of impact. For example, for a simple edge supported composite plate of constant thickness, the BVID impact energy will be different if the impact point is the plate centre or if it is near a supported edge.

Consequently, the optimization of a composite with the damage tolerance concept can be very complex. In particular, if this optimization is carried out using experimental tests, a large number of tests will be necessary, involving time consuming, expensive processes. For example, a series of each component is required to obtain the BVID impact energy at each impact location, and afterwards the residual strength, which has to be compared to required loads.

So the development of numerical tools is essential to the aerospace industry to optimize composite structures according to the damage tolerance concept. And the challenge is to simulate, with the same model, damage during impact and in particular permanent indentation, and the residual mechanical characteristics after impact, in order to be able to numerically optimize design of composite structures with impact damage tolerance. 


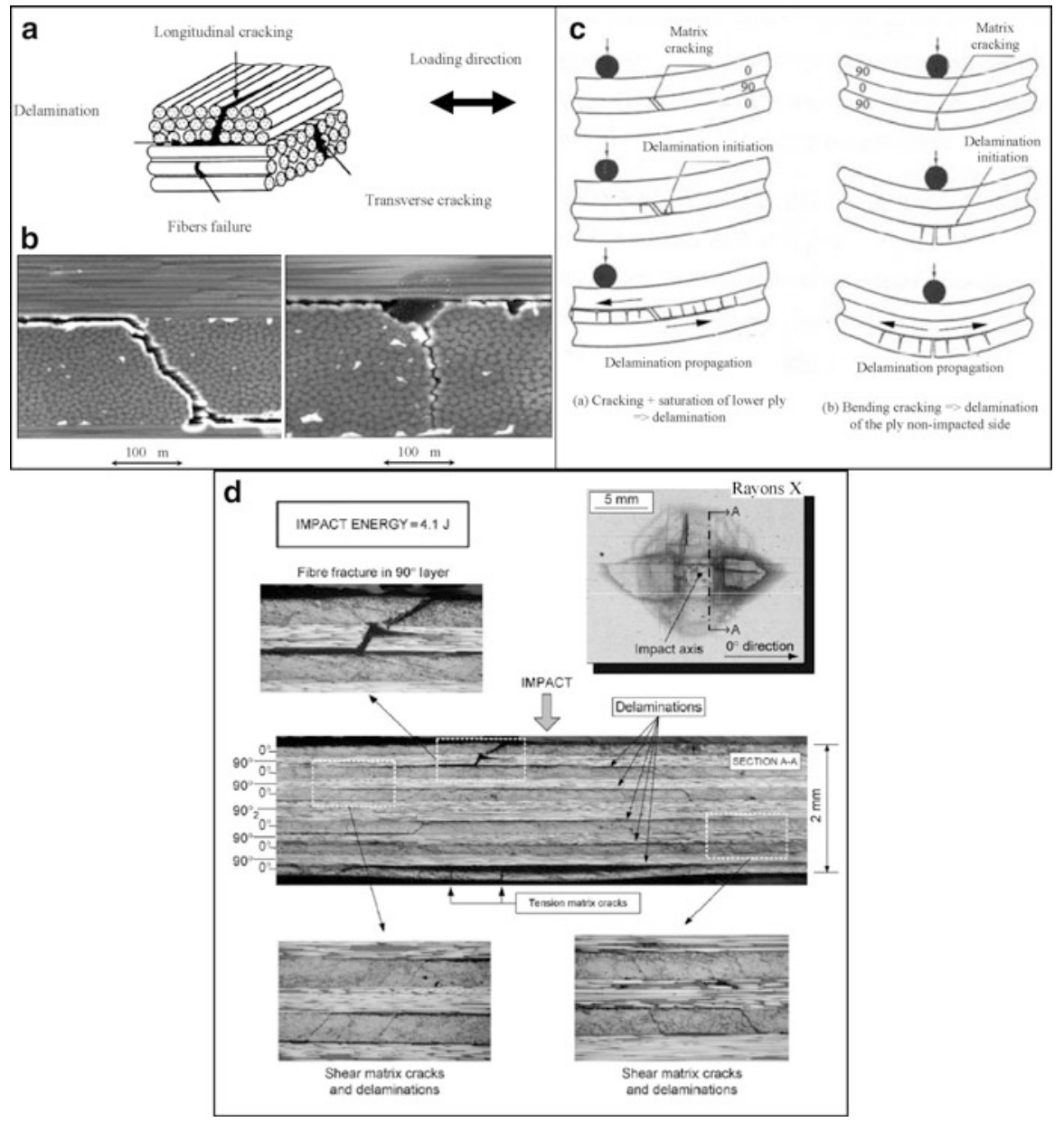

Fig. 2 Impact damage in UD composite: (a) different damage types [4], (b) damage photos [2], (c) principle diagram of interaction between intra- and inter-laminar damage [13] and (d) impact damage [14]

\subsection{Impact Damage}

A low velocity/low energy impact on a UD composite laminate induces three types of damage: matrix cracks, fiber fractures and delamination (Fig. 1) [2, 4, 13].

The first damage to appear is conventionally matrix cracking. When this damage grows, delamination quickly occurs. An interaction between these two damage phenomena is clearly visible during the impact tests (Fig. 2). This interaction is crucial to explain the very original morphologyof the delaminated interfaces 
a

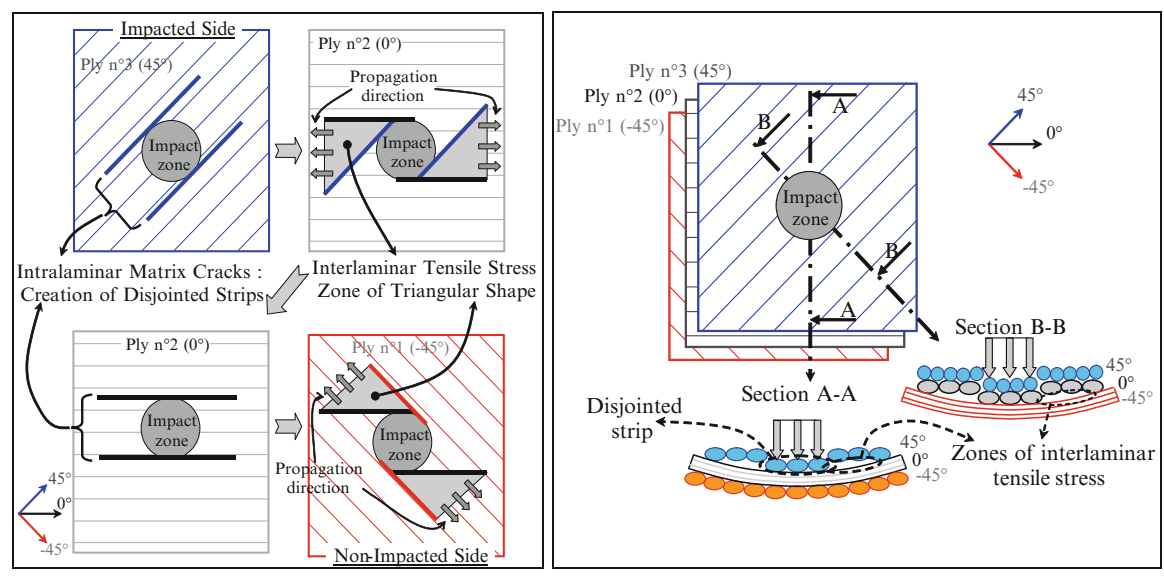

Fig. 3 Mechanism of delamination formation proposed by Renault [15]

in the thickness of the plate: a C-scan investigation shows delamination as twin triangles (Fig. 20) [8, 15] with a size growing from the impacted side to the nonimpacted side.

This formation of twin triangles is illustrated by Renault [15] on a simple stacking sequence $[-45,0,45]$ (Fig. 3). The impact damage begins with the development of matrix cracks in the impact zone below the impactor. These matrix cracks grow up during the loading in the fibers direction. Therefore, in each ply, a strip of fibers and resin disjoints and slides in the normal direction of this ply (z). This disjointed strip creates an inter-laminar zone of tension stress between two consecutive plies and can induce in this zone the formation of a delamination (Fig. 3a). The zone of tension stress, limited by the disjointed strips of the two adjacent plies, has triangular shape with a size growing from the impacted side to the non-impacted side. Figure $3 \mathrm{~b}$ illustrates the inter-laminar zones of tension stress between the $-45^{\circ} / 0^{\circ}$ and $0^{\circ} / 45^{\circ}$ plies.

This scenario enables us to illustrate some originalities of the impact damage morphology, such as delamination aligned with the fibers of the lower ply or the generally conical shape of delamination. However some questions remain subject to debate. For example, the type of delamination propagation modes (mode I, II or III) or the physical phenomenon responsible for permanent indentation are some of the numerous questions which are still largely open. To answer such questions, an impact finite element (FE) model has been created.

The key point for an impact model is interaction between intra-laminar damage, namely matrix cracks, and fiber failure, and inter-laminar damage, namely delamination. Some models in the literature [5-7, 16, 17] take into account this interaction due to explicit relations between the damage variables of matrix cracking in the ply and the damage variables of delamination between plies. Another way to 


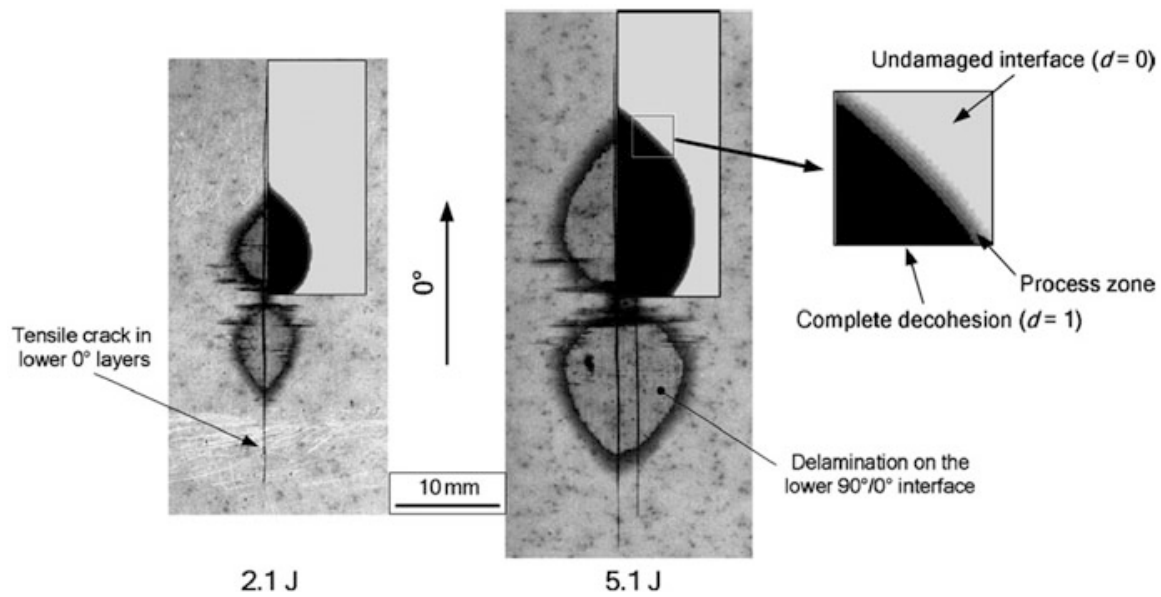

Fig. 4 Comparison of numerical predictions and experimental results [19]

model this interaction is to allow for the discontinuity created by matrix cracks, in order to naturally account for this interaction $[5,18,19]$. Indeed this discontinuity seems essential for the formation of impact damage [20] and should be modeled to correctly simulate this damage morphology.

\subsection{Impact Modeling of Composite Laminate}

Many authors have studied impact behavior of composite structures and their effects on residual strength, both experimentally $[1-4 \ldots]$, as well as numerically [5-8 ... $]$, but a lot of work is still needed to improve modeling of damage developing during impact on composite laminates and to numerically assess their residual mechanical characteristics in order to optimize their design. Therefore this short bibliography is not intended to be exhaustive, and the authors invite interested readers to consult review papers of Abrate [1], Davies and Olsson [21] or Wisnom [20], but only to show some modeling with different approaches.

For instance, a model proposed by Aymerich et al. [19] has simulated clustered $\left(\left[0_{3} / 90_{3}\right]_{S} \&\left[90_{3} / 0_{3}\right]_{S}\right)$ and dispersed $\left([0 / 90]_{3 S}\right)$ cross-ply laminates subjected to increasing levels of impact loads and have compared these numerical results to experimental observations. Cohesive interface elements have been used in 3D finite element models to simulate delamination but no matrix cracking is taken into account. They obtain a good correlation of the force-time histories, the sequence of damage events, the energy threshold and the size and shape of delamination. They conclude that initiation and growth of delamination are globally well reproduced in spite of a lack of simulation of the pre-existing matrix cracks in adjacent layers (Fig. 4). 


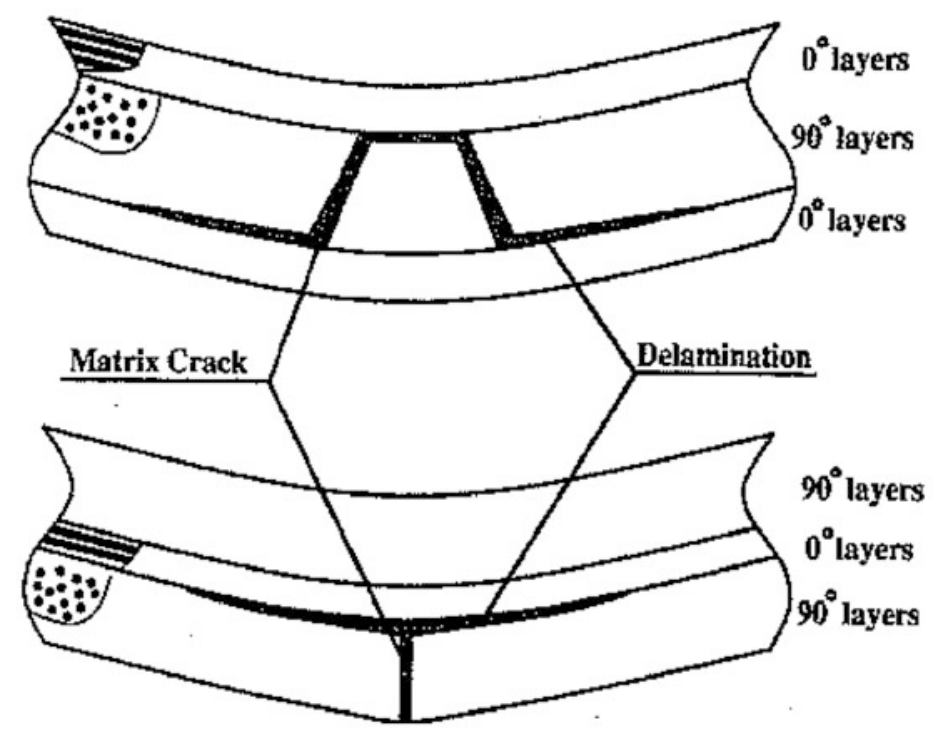

Fig. 5 Impact damage mechanisms. Top: delamination induced by inner shear cracks. Bottom: delamination induced by surface bending crack [6]

It is generally established in the literature $[20,22,23]$ that matrix cracking seems to have a precursor role in delamination. Nevertheless Aymerich et al. conclude that the poor correlation between simulated and experimental delamination on the dispersed stacking sequence needs to be identified and in our opinion these discrepancies could be due to this lack of a matrix cracking model. For example, Choi and Chang [6] studied the onset of delamination during impact loading and showed a coupled criterion of delamination and matrix cracking is necessary to explain delamination. In particular, they introduced 2 types of delamination: delamination induced by inner shear cracks and delamination induced by surface bending cracks (Fig. 5).

They used a delamination criterion which decreases in the presence of matrix cracks and delamination is supposedly impossible without matrix cracking of the lower or upper ply. This idea is also used by Ladeveze et al. [24] who showed the coupling between inter-ply and intra-ply damage using a micro-mechanical model. Indeed they show that interface damage depends largely on matrix micro-cracking and local delamination (Fig. 6).

Moura and Gonçalves [7] have built an interface element with softening behavior to simulate delamination, as well as matrix cracking. These interface elements of matrix cracking are situated only where damage is detected during an experimental test, which is of course a limitation for a predictive model. The simulations are quite in accordance with experiments, although the delamination is overestimated and the matrix cracks underestimated. 


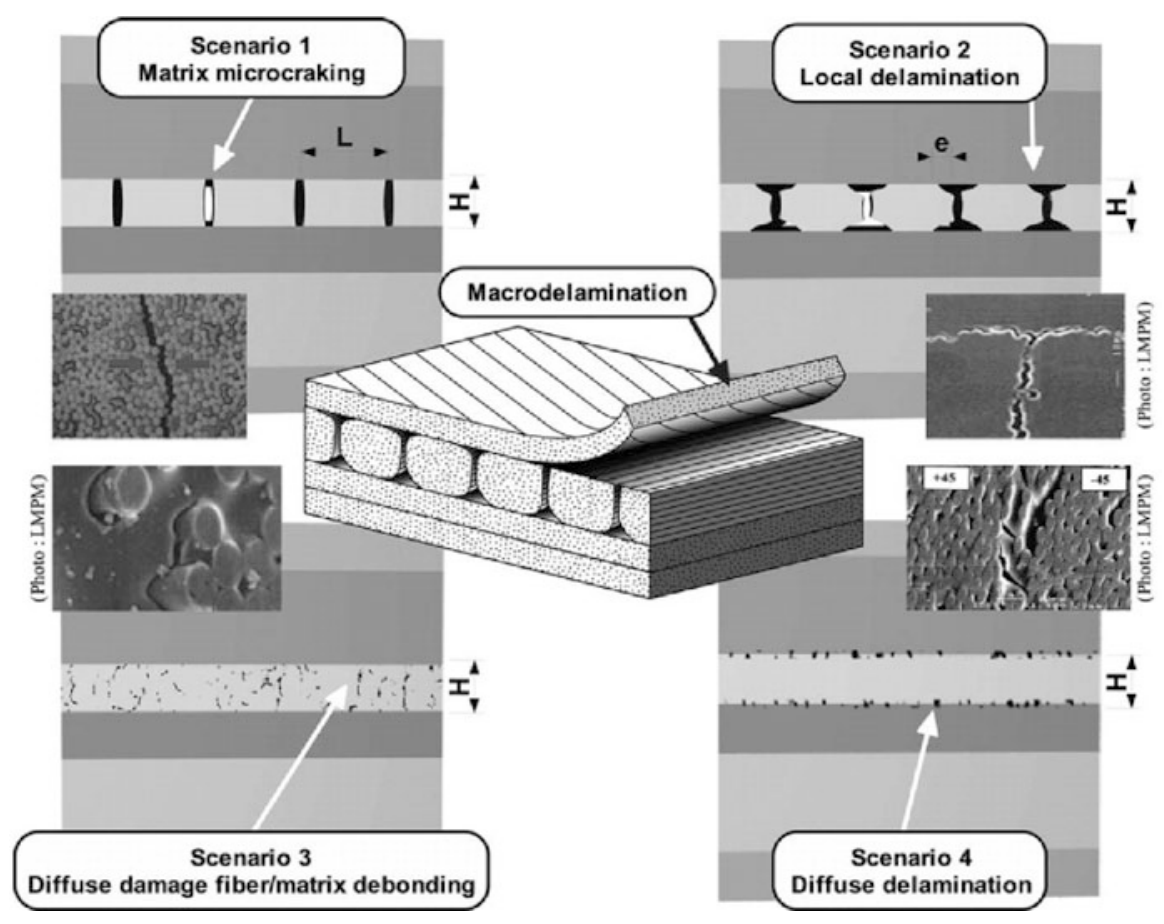

Fig. 6 The mechanisms of degradation on the micro-scale [24]

Zhang et al. [25] performed a similar study on $\left[0_{4} / 90_{4}\right]_{S}$ carbon epoxy laminate plates. They showed that the modeling of the main matrix crack of the $0^{\circ}$ ply, nonimpacted side, is sufficient to obtain the correct size and shape of the delamination of the first interface non-impacted side. A previous study by Lammerant and Verpoest [26] have shown in the same way that the delamination shape depends primarily on the first matrix cracks and have concluded that the existence of matrix cracks cannot be disregarded when calculating delamination development.

So if the coupling between matrix cracking and delamination seems necessary to properly simulate delamination development during an impact, some numerical solutions seem possible. The coupling can be direct; the delamination criterion depends on the matrix cracking of the lower and upper plies, which induces a numerical exchange between delamination elements and matrix cracking elements. Or the coupling can be indirect by considering that the intra-ply damage representation is good enough to account for the intra-ply degradation and to naturally take this coupling into account. In general, this is the method adopted when matrix cracking is simulated using interface elements and this is the approach taken in the present work.

Nevertheless some numerical studies in the literature seem to give good correlation with experiments in spite of the lack of coupling between matrix cracking 
and delamination. For example, Tita et al. [27] simulated low velocity impacts on thin composite laminates with complex stacking sequence $[45 /-45 / 45 / 0 / 90]_{S}$ with uncoupled intra-ply and inter-ply damage models based on continuum damage mechanics. The simulation agrees relatively well with the experimental data, even if authors do not correlate the delaminated interfaces.

Johnson et al. [28] combined continuum damage mechanics for in-plane failure with interface elements based on the critical energy release rate for delamination. This model seems to correlate well with the dynamic response and the damage zone. Iannucci and Willows [29, 30] used interface elements to model delamination between plies, based on the critical energy release rate, and continuum damage mechanics to take into account intra-ply damage based on total energy dissipated for each damage mode. Afterwards this model was used to simulate impact on woven composite plate but due to computational constraints, the plate was only divided into two sub-laminates and only one delaminated interface could be obtained. Nevertheless, the numerical correlation with the experimental results seems relatively good.

Before finishing with this bibliography on low velocity impact modeling, and without performing a bibliography on models of compression after impact, Faggiani and Falzon's [17] work should be noted, because as far as we know, it is the only model in the literature used to simulate impact and compression after impact tests on a real structure. Indeed Faggiani and Falzon simulate the impact damage and the residual strength under compression of a stiffened composite panel. To do this, an intra-laminar damage model, based on continuum damage mechanics, is coupled with interface elements, based on the critical energy release rate. The permanent indentation after impact of the panel is also simulated using nonlinear shear formulation of the intra-laminar damage model. Faggiani and Falzon observe that this deformation should be significant in predicting the compression after impact response of the panel. The numerical correlation on time-force history, on damage shape and on residual strength seems to be good. Nevertheless insufficient knowledge of the real impact damage obtained experimentally makes it difficult to evaluate the reliability of this model. In particular the ultrasonic investigations (C-Scan) given in this study are not experimentally reproducible to determine the delaminated interface shapes and other experimental examinations, as micrographic cuts or subsequent inter-correlation using images during compression after the impact test, are needed to evaluate the reliability of the model. However this conclusion is generally valid for many models in the literature and experimental investigations of impact tests are often insufficient to evaluate the domain of their validity. Moreover this correlation, between numerical and experimental results is fundamental to drive a "test-calculation dialogue", i.e. to be able to validate a model through experimental results, as well as to better understand the experimental results via numerical results. 


\subsection{Outline}

The goal of this study is to drive a "test-calculation dialogue" on the composite impact test. At the same time it is necessary to perform a refined experimental study of the different impact damage types, and to build a numerical model able to simulate these observations. Indeed the bibliography shows a general lack of detailed validation of impact modeling and an original aspect of the present study is to use refined, complementary experimental data to build and validate a numerical model. The experimental examinations are used, such as C-scans of impacted and non-impacted sides for different impact energy levels, micrographic cuts in different planes, evaluation of permanent deformation of the plate on impacted and nonimpacted sides, or more standard force-displacement curves during impact.

The first section (Sect. 3) deals with the modeling principle of the different damage types developed during impact. The three most common damage types are simulated: matrix cracking, delamination and fiber failures. The modeling choices will be presented and explained using the experimental examinations and the bibliography results. In particular, original formulations are proposed for matrix cracking, fiber failure, and permanent indentation modeling.

The next section (Sect. 4) deals with the experimental validation. An impact reference case has been chosen to evaluate the accuracy of the proposed model. In practical terms, this step is interdependent with the previous section and multiple comparisons are necessary between the numerical results and the experimental observations: this is the "test-calculation dialogue" principle. Nevertheless, these two steps are separated in order to simplify the presentation. Subsequently, the model is used for a more in-depth analysis of the distribution of dissipated energy, or fracture modes of delamination, that cannot be directly estimated from experiments.

And the last section (Sect. 5) deals with numerical validation. Other experimental impact tests have been performed with different impact energy levels, different boundary conditions, different stacking sequences, or different impact velocities, in order to evaluate the influence of each of these parameters, and also to estimate the validity domain and limitations of the model.

Finally the conclusions will show the advantages of the "test-calculation dialogue" in building a numerical model able to represent the different experimental observations.

\section{Modeling Principle}

\subsection{Introduction}

This section deals with the presentation of the modeling principle of the different impact damage types developed during impact [31]. Intra-laminar damage, i.e. matrix cracks, is conventionally simulated using interface elements based on failure 


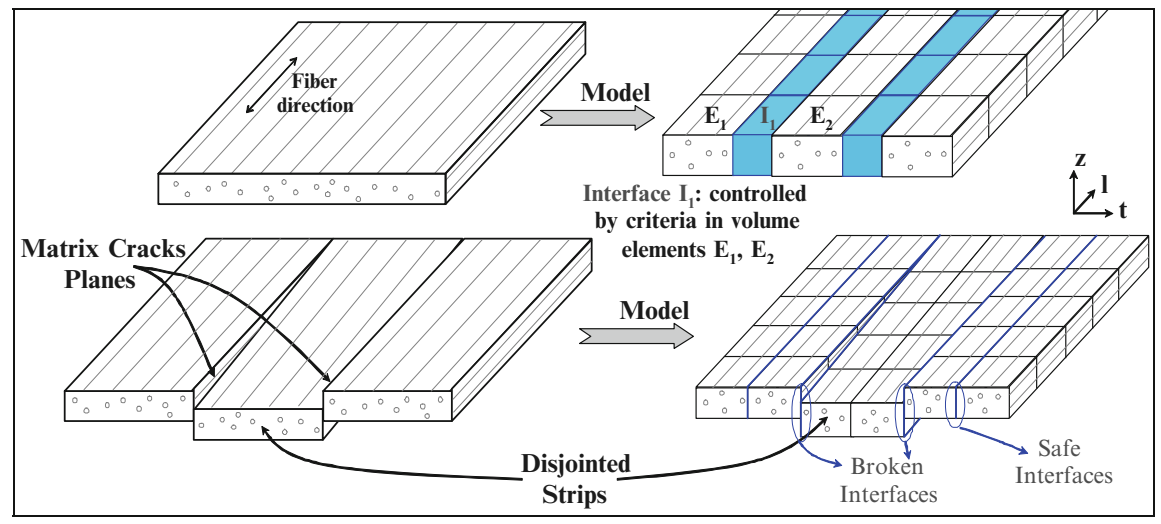

Fig. 7 Model of the ply meshed with longitudinal strips

criterion, but unlike the conventional approach, in our study, the fiber criterion is calculated in the neighboring volume elements to avoid stress concentrations. Fiber failure is simulated using conventional continuum damage mechanics, but with original formulation between the integration points of the $3 \mathrm{D}$ element to dissipate energy at a constant release rate per unit area. Inter-laminar damage, i.e. interface delamination, is conventionally simulated using interface elements based on fracture mechanics. And permanent indentation is modeled using the matrix cracking elements and an unconventional "plastic-like" behavior.

These modeling choices have been adopted in order to take into account the experimental observations. This is why some modeling choices are currently used in the literature, such as the inter-laminar interfaces to simulate delamination, and others are original, such as the "plastic-like" modeling of the matrix cracking interface elements to simulate permanent indentation.

\subsection{Matrix Crack Modeling}

Matrix cracking modeling should be able to simulate important matrix cracks as observed in the micrographs (Figs. 2b and 12) [1, 4, 20]. Moreover it should be able to simulate the interaction between matrix cracking and delamination damage which is a crucial point in impact damage formation. Then each ply is meshed separately using little longitudinal strips with one volume element in the ply thickness (Fig. 7).

Afterwards these little strips are connected together with zero-thickness interface elements normal to the transverse direction. These interface elements can account for matrix cracks in the thickness of the ply. Nevertheless this type of mesh presents some drawbacks: 
- This mesh is complicated with uniform size in the impact zone. Nevertheless, it is possible to simulate an impact on a real structure using a multi-scale approach: the model described above for the area concerned with impact damage, and a conventional FE model for the remaining structure [32].

- This mesh can only simulate cracks occurring through the entire thickness of the ply and is not able to simulate small, diffusive matrix cracks. This means the propagation of matrix cracks within the ply thickness is assumed to be instantaneous. Then, if the ply thickness is not too great, the propagation of a matrix crack in the thickness takes place very quickly and its effect on the creation of the impact damage should remain local.

- This mesh can only simulate cracks normal to interfaces. However matrix cracks due to out-of-plane shear stress $\left(\tau_{t z}\right)$, are globally inclined at $45^{\circ}$. This hypothesis avoids the use of an overly complex mesh, and seems reasonable if the ply thickness is small compared to the laminate thickness.

- The mesh size imposes the maximum density of matrix cracks in the transverse direction of the ply. This drawback could seem very important but the presence of one matrix crack, i.e. of a broken interface, should unload the neighboring interfaces in the transverse direction and prevent their breaking. Indeed the matrix cracks, taken into account in this model, are only the largest ones, i.e. those running through the entire ply thickness, and not the little, diffuse matrix cracks. This means that the model does not take into account the network of little matrix cracks because the effect of these diffuse matrix cracks seems small compared to those running through the entire thickness.

Another consequence of this imposed maximum density of matrix cracks is the choice of the failure criterion. It would be interesting to use fracture mechanics, in addition to interface elements, to simulate the critical energy release rate [33]. But in this case, the mesh density, which is imposed a priori, induces the maximum energy possible to dissipate, except of course if the mesh is fine enough to simulate each crack. As it is not possible to simulate each matrix crack (Fig. 12) and very difficult to evaluate the maximum number of possible cracks, a model has been chosen without energy dissipation. The model ignores the energy dissipated by matrix cracking, even if a part of this energy should be included in the energy dissipated by delamination. Indeed, the DCB (Double Cantilever Beam) test, which is used to evaluate the critical energy release rate for delamination, is a comprehensive test taking into account all the damage types $[34,35]$. Then the energy dissipated by the matrix cracks, accompanying the delamination, is taken into account. Nevertheless the consequence of this non dissipative model should be evaluated with other experimental tests. Another solution would be to use cohesive crack modeling to allow multiple matrix cracks per element, as proposed by Raimondo et al. [36].

Then the interface degradation is abrupt: if the material is safe, the stiffness of these matrix cracking interfaces is considered to be very high (typically $10^{6} \mathrm{MPa} / \mathrm{mm}$ ) and this stiffness is set to zero if matrix cracks exist. And this failure 
is driven by standard criterion, similar to Hashin's criterion [37, 38], calculated in the neighboring volume elements:

$$
\left.\frac{\left\langle\sigma_{t}\right\rangle^{+}}{\sigma_{t}^{f}}\right)^{2}+\frac{\tau_{l t}^{2}+\tau_{t z}^{2}}{\left(\tau_{l t}^{f}\right)^{2}} \leq 1
$$

Where $\sigma_{\mathrm{t}}$ is the transverse stress, $\tau_{\mathrm{lt}}$ and $\tau_{\mathrm{tz}}$ the shear stresses in the (lt) and (tz) planes, $\left\langle>+\right.$ the positive value, $\sigma_{\mathrm{t}}^{\mathrm{f}}$ the transverse failure stress and $\tau_{\mathrm{lt}}^{\mathrm{f}}$ the shear failure stress of the ply.

This conventional quadratic criterion [38] is written with stresses at each Gauss point of the two neighboring volume elements and the interface is broken when the criterion is reached at one of these points. This is an original point of the proposed model and can be considered as an average stress over a distance which depends on the mesh size. This mesh sensitivity will have to be studied further; this work is currently in progress.

\subsection{Fiber Failure Modeling}

For the fiber failures observed after impact (Fig. 12), there is no evidence of distributed fiber damage. Moreover due to the high critical energy release rate of fiber failure [39], it is necessary to dissipate this energy in the model. Additional interface elements could be used but would result in very complex meshing. Therefore, to avoid the use of such interfaces, fiber failure is taken into account using conventional continuum damage mechanics but with original formulation between the integration points of the element to produce a constant energy release rate per unit area. This approach can be compared to methods based on characteristic element length which makes possible mesh-size independent modeling [36, 40-42].

Therefore, to be able to produce the critical energy release rate due to fiber fracture per unit area of crack, the behavior laws of the eight integration points of a volume element are managed together. In this case, the law is written only in opening mode I (Fig. 8), but could be generalized with other fracture modes:

$$
\int_{V}\left(\int_{0}^{\varepsilon^{1}} \sigma_{l} \cdot d \varepsilon_{l}\right) \cdot d V=S \cdot G_{I}^{f}
$$

Where $\sigma_{1}\left(\varepsilon_{1}\right)$ is the longitudinal stress (strain), $\mathrm{V}(\mathrm{S})$ the volume (section) of the element, $\varepsilon^{1}$ is the strain of total degradation of the fiber stiffness (Fig. 8) and $\mathrm{G}_{\mathrm{I}}{ }^{\mathrm{f}}$ the energy release rate in opening mode in fibers direction. It can be observed that volume elements with 8 Gauss points have been chosen to obtain good bending behavior with only one element in theply thickness. 
a

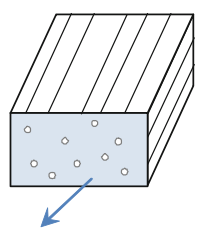

Section : S

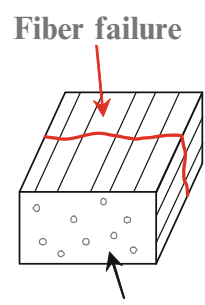

Volume : V b

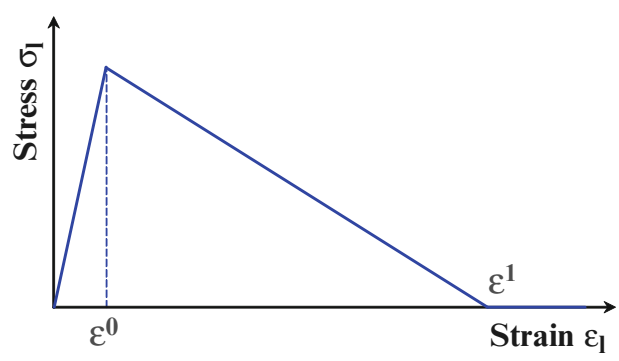

Fig. 8 Principle of fiber failure (a) and behavior law in the longitudinal direction (b)

Afterwards, the stiffness in fibers is degraded using a damage variable $\mathrm{d}_{\mathrm{f}}$ :

$$
\sigma_{l}=\left(1-d_{f}\right) \cdot\left(H_{l l} \cdot \varepsilon_{l}+H_{l t} \cdot \varepsilon_{t}+H_{l z} \cdot \varepsilon_{z}\right)
$$

Where $\mathrm{H}_{l l}, \mathrm{H}_{\mathrm{lt}}$ and $\mathrm{H}_{\mathrm{lz}}$ are the stiffness values in the longitudinal direction. And this damage variable is conventionally calculated according to the longitudinal strain in order to obtain a linear decrease of the longitudinal stress (Fig. 8) [42]:

$$
d_{f}=\frac{\varepsilon^{1} \cdot\left(\varepsilon_{l}-\varepsilon^{0}\right)}{\varepsilon_{l} \cdot\left(\varepsilon^{1}-\varepsilon^{0}\right)}
$$

Where $\varepsilon^{1}$ is the strain of total degradation of the fiber stiffness calculated using the Eq. 2 and $\varepsilon^{0}$ is the strain of damage initiation.

Another originality of this fiber failure approach is to initiate the damage when the maximum of the longitudinal strains calculated at the element nodes reaches the fiber failure strain $\varepsilon_{1}^{\mathrm{f}}$. The use of extrapolated strains at element nodes, rather than direct strain values at integration points, makes it easier to take into account the bending behavior of each ply with only one finite volume element in the thickness.

Moreover fiber failure due to compression or shear stress is not taken into account in this release of the model. Indeed this model has been based on a reference case (cf. Sect. 4) where these types of fiber failure does not seem appear. Nevertheless these failure types should be taken into account for other impact tests, such as impacts with different boundary conditions or with different stacking sequences (cf. Sect. 5). This work is currently in progress and could partially explain the discrepancies observed in these simulations. 


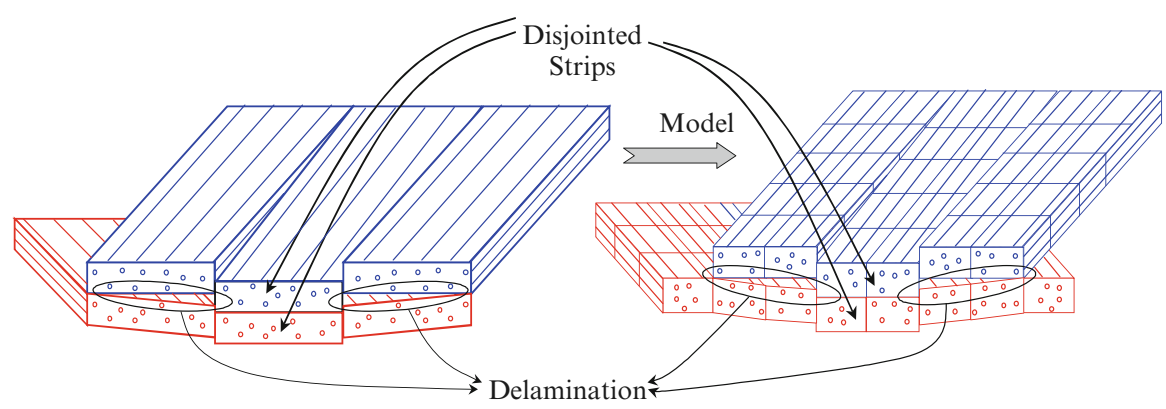

Fig. 9 Principle of the interface model between plies

\subsection{Delamination Modeling}

Delamination damage consists of important cracks between plies (Figs. 12 and 18) $[6,10,13]$. It is typically modeled with cohesive interface elements based on fracture mechanics $[33,43]$. This modeling choice makes it possible to correctly take experimental observations into account and has been adopted in this study.

Then after the different plies are meshed with volume elements and matrix crack interface elements, two consecutive plies are joined using zero-thickness interface elements (Fig. 9). These delamination interface elements are conventionally softening interfaces $[33,43]$ of zero thickness driven by fracture mechanics. They are written in mixed fracture mode (mode I, II, III) to simulate the energy dissipated by delamination. Moreover the shearing (II) and tearing (III) fracture modes are combined and in the following, the term of mode II will be abusively used to name the fracture modes II and III. And in order to represent the overlap of 2 consecutive plies, the $0^{\circ}$ and $90^{\circ}$ plies are meshed with square elements and the $45^{\circ}$ and $-45^{\circ}$ plies are meshed with diamond-shaped elements (Fig. 10).

Then, an equivalent displacement is written in order to simulate a linear coupling law between the fracture modes:

$$
d_{e q}=\sqrt{\left.\left.\left(\left\langle d_{I}\right\rangle^{+}\right)^{2}+\frac{d_{I}{ }^{0}}{d_{I I}{ }^{0}} \cdot d_{I I}\right)^{2}+\frac{d_{I}{ }^{0}}{d_{I I I}{ }^{0}} \cdot d_{I I I}\right)^{2}}
$$

Where $\mathrm{d}_{\mathrm{I}}, \mathrm{d}_{\mathrm{II}}$ and $\mathrm{d}_{\mathrm{III}}$ are the displacements respectively in the $\mathrm{z}, 1$ and $\mathrm{t}$ directions, $\mathbf{d}_{\mathrm{I}}^{0}, \mathbf{d}_{\mathrm{II}}^{0}$ and $\mathbf{d}_{\mathrm{III}}^{0}$ are the critical displacements respectively in the $\mathrm{z}, 1$ and $\mathrm{t}$ directions, calculated according to failure stresses (Fig. 11):

$$
d_{I}^{0}=\frac{\sigma_{I}^{0}}{k_{I}^{0}} ; \quad d_{I I}^{0}=\frac{\sigma_{I I}^{0}}{k_{I I}^{0}} ; \quad d_{I I I}^{0}=\frac{\sigma_{I I I}^{0}}{k_{I I I}^{0}}
$$


Fig. 10 Overlap of ply mesh
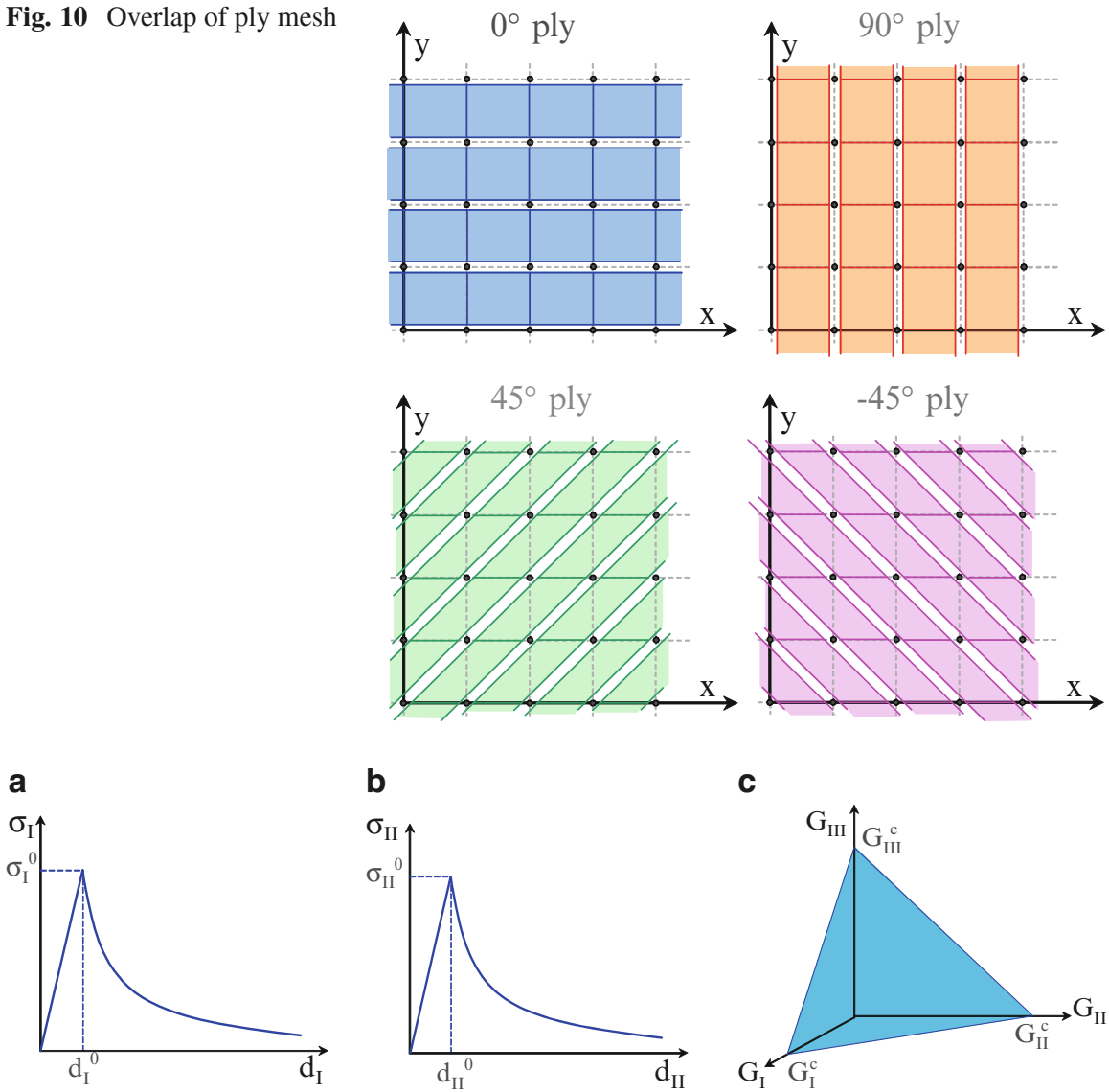

Fig. 11 Evolution of the stress-displacement curves in mode I (a) and II (b) and linear mixed fracture mode (c)

Where $\mathbf{k}_{\mathrm{I}}^{0}, \mathbf{k}_{\mathrm{II}}^{0}$ and $\mathbf{k}_{\mathrm{III}}^{0}$ are the stiffness values respectively in the $\mathrm{z}, \mathrm{l}$ and $\mathrm{t}$ directions and $\sigma_{\mathrm{I}}^{0}, \sigma_{\mathrm{II}}^{0}$ and $\sigma_{\mathrm{III}}^{0}$ are the critical stresses respectively in the $\mathrm{z}, 1$ and $\mathrm{t}$ directions. And the 2 shear directions are assumed to be equivalent:

$$
d_{I I I}{ }^{0}=d_{I I}{ }^{0} ; \quad k_{I I I}{ }^{0}=k_{I I}{ }^{0} ; \quad \sigma_{I I I}{ }^{0}=\sigma_{I I}{ }^{0}
$$

And to avoid additional material parameters, the critical stresses are assumed to be equal to the failure stresses of the ply:

$$
\sigma_{I}^{0}=\sigma_{t}^{f} ; \quad \sigma_{I I}^{0}=\sigma_{I I I}^{0}=\tau_{l t}^{f}
$$


Table 1 Material parameters

\begin{tabular}{lllllll}
\hline $\mathrm{E}_{\mathrm{l}}^{\mathrm{t}}(\mathrm{GPa})$ & $\mathrm{E}_{\mathrm{l}}^{\mathrm{c}}(\mathrm{GPa})$ & $\mathrm{E}_{\mathrm{t}}(\mathrm{GPa})$ & $v_{\mathrm{lt}}$ & $\mathrm{G}_{\mathrm{lt}}(\mathrm{GPa})$ & $\sigma_{\mathrm{t}}{ }^{\mathrm{f}}(\mathrm{MPa})$ & $\tau_{\mathrm{lt}}{ }^{\mathrm{f}}(\mathrm{MPa})$ \\
\hline 130 & 100 & 10 & 0.29 & 4.8 & 50 & 90 \\
\hline$\varepsilon_{1}^{\mathrm{f}}$ & $\mathrm{G}_{\mathrm{I}}{ }^{\mathrm{d}}(\mathrm{N} / \mathrm{mm})$ & $\mathrm{G}_{\mathrm{II}}{ }^{\mathrm{d}}(\mathrm{N} / \mathrm{mm})$ & $\mathrm{G}_{\mathrm{I}}{ }^{\mathrm{f}}(\mathrm{N} / \mathrm{mm})$ & $\varepsilon_{\mathrm{t}}{ }^{0}$ & $\mathrm{k}_{\mathrm{t}}(\mathrm{MPa} / \mathrm{mm})$ \\
\hline 0.016 & 0.5 & 1.6 & 133 & 0.02 & 10,000 \\
\hline
\end{tabular}

Then a decreasing exponential law is chosen to avoid the shock of the final fracture:

$$
\left\{\begin{array}{l}
\sigma_{I}=\sigma_{I}^{0} \cdot \exp \left(-\beta \cdot\left(d_{e q}-d_{I}^{0}\right)\right) \frac{d_{I}}{d_{e q}} \\
\sigma_{I I}=\sigma_{I I}^{0} \cdot \exp \left(-\beta \cdot\left(d_{e q}-d_{I I}{ }^{0}\right)\right) \frac{d_{I I}}{d_{e q}} \frac{d_{I}{ }^{0}}{d_{I I}{ }^{0}} \\
\sigma_{I I I}=\sigma_{I I I}{ }^{0} \cdot \exp \left(-\beta \cdot\left(d_{e q}-d_{I I I}{ }^{0}\right)\right) \frac{d_{I I I}}{d_{e q}} \frac{d_{I}^{0}}{d_{I I I}{ }^{0}}
\end{array}\right.
$$

Where the coefficient $\beta$ is determined to reproduce the energy release rate $\mathrm{G}_{I}{ }^{\mathrm{d}}$ in mode I under the stress-strain curve and $\mathrm{G}_{\mathrm{II}}{ }^{\mathrm{d}}$ in mode II and III (Fig. 11):

$$
\beta=\frac{1}{\frac{G_{I}{ }^{d}}{\sigma_{I}{ }^{0}}-\frac{d_{I}{ }^{0}}{2}}
$$

and the use of the same $\beta$ coefficient for modes I, II and III imposes:

$$
\mathrm{k}_{\mathrm{II}}^{0}=\mathrm{k}_{\mathrm{III}}{ }^{0}=\frac{\left(\sigma_{\mathrm{II}}{ }^{0}\right)^{2}}{\mathrm{G}_{\mathrm{II}}{ }^{\mathrm{d}}}\left(\frac{1}{2}+\frac{1}{\beta \cdot \mathrm{d}_{\mathrm{I}}^{0}}\right)
$$

And the last undetermined coefficient $\mathrm{k}_{\mathrm{I}}^{0}$ (Table 1 ) is considered very high (typically $10^{6} \mathrm{MPa} / \mathrm{mm}$ ). It can be observed that a linear mixed mode of fracture is imposed (Fig. 11c) due to the choice of the equivalent displacement (Eq. 5).

This model adopted for delamination is often used in the literature [5, 20, 33] even if this expression (Eq. 5) is original. The definition of this equivalent displacement enables us to automatically compare all the possible mode ratios of displacement and how much energy should still be available to dissipate until total fracture occurs. Indeed during complex loading, with large variation in the mode ratio, it is not so easy with conventional formulation to evaluate this remaining energy to be dissipated $[33,44]$. 


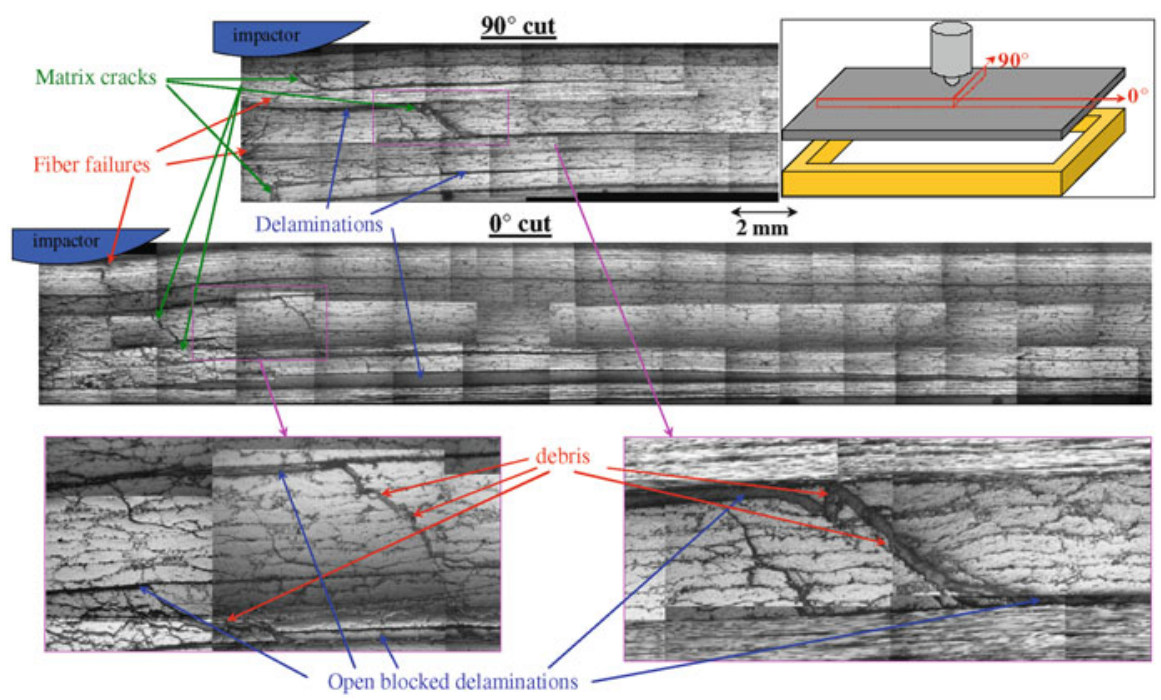

Fig. 12 Micrographic cuts after 25 J-impact

\subsection{Permanent Indentation}

Permanent indentation, i.e. the dent depth of the impact point, is a crucial aspect for the certification of composite structures with damage tolerance concepts [10-12]. Indeed the size of such an indentation determines whether impact damage can be detected or not. Moreover, in order to be able to use this model in the future to totally simulate impact damage tolerance design, permanent indentation has been taken into account through the intra-ply interfaces. Although some authors have worked on the permanent indentation phenomenon [3, 45-50], a lot of work is still necessary to physically understand this phenomenon and to correctly model it. Currently this residual deformation after impact is explained, for thermoset resin as epoxy, with "plasticity". Indeed this type of resin presents important permanent deformation after testing, particularly under shear stress [51], similar to plasticity deformation. But another phenomenon responsible for permanent indentation seems to be impact debris in $45^{\circ}$ cracks through the ply thickness (Fig. 12) [52]. This phenomenon has been taken into account in the present model using an original "plastic-like" behavior in the matrix cracking elements.

In order to study the phenomenon of permanent indentation, laminated plate was cut after being embedded in resin to prevent relaxation (Fig. 12). These photos were taken after a $25 \mathrm{~J}$-impact test on a UD laminate (cf. Sect. 4.1). In this photo, debris in the $45^{\circ}$ matrix cracks seem to block their closure and to hold the adjacent delamination open. This phenomenon is schematically presented in Fig. 13 and could explain part of permanent indentation. 
Fig. 13 Principle of producing permanent indentation

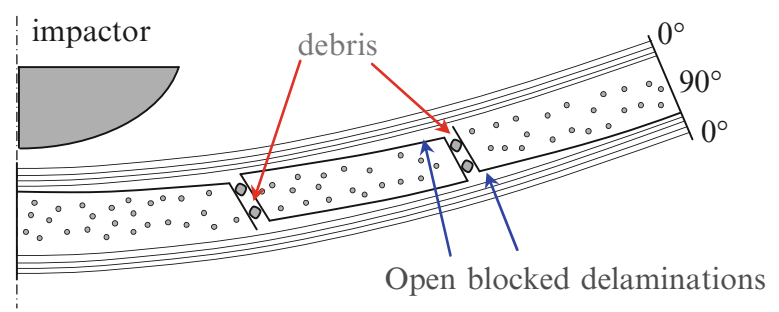

a

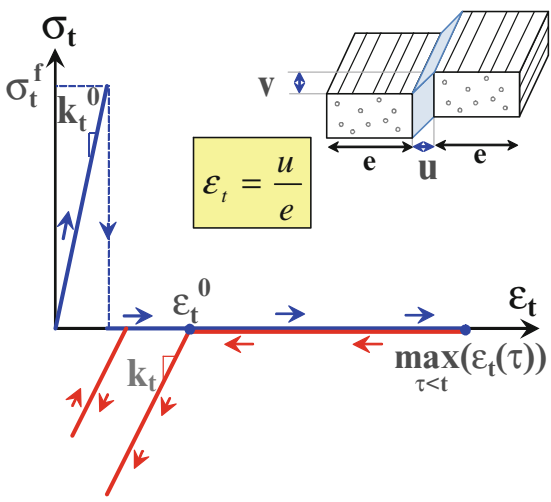

b

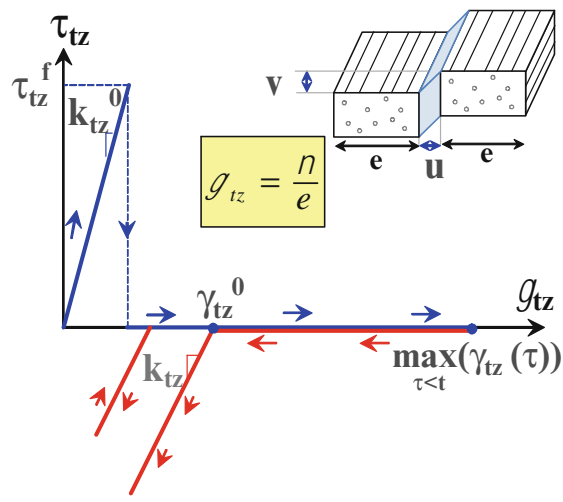

Fig. 14 Permanent indentation model in tension (a) and shear (b)

Nevertheless, this phenomenon cannot fully explain permanent indentation and other phenomena, such as "plasticity" or compaction of resin (due to initial porosity) or friction of delaminated interfaces, matrix cracks or fiber/resin debonding, may play a role. However the permanent indentation seems to a great extent to be due to the blockage of debris and this phenomenon was taken into account in the proposed model. To do this, a "plastic-like" model was introduced in the matrix cracking interfaces in order to limit their closure after failure under tension $\left(\sigma_{t}\right)$ and out-ofplane shear $\left(\tau_{\mathrm{tz}}\right)$ (Fig. 14):

$$
\begin{aligned}
& \left\{\begin{array}{l}
\varepsilon_{t} \geq \min \left(\max _{\tau \leq t}\left(\varepsilon_{t}(\tau)\right), \varepsilon_{t}{ }^{0}\right) \Rightarrow \sigma_{t}=0 \\
\varepsilon_{t}<\min \left(\max _{\tau \leq t}\left(\varepsilon_{t}(\tau)\right), \varepsilon_{t}{ }^{0}\right) \Rightarrow \sigma_{t}=k_{t} \cdot\left(\varepsilon_{t}-\min \left(\max _{\tau \leq t}\left(\varepsilon_{t}(\tau)\right), \varepsilon_{t}{ }^{0}\right)\right)
\end{array}\right. \\
& \left\{\begin{array}{l}
\gamma_{t z} \geq \min \left(\max _{\tau \leq t}\left(\gamma_{t z}(\tau)\right), \gamma_{t z}{ }^{0}\right) \Rightarrow \tau_{t z}=0 \\
\gamma_{t z}<\min \left(\max _{\tau \leq t}\left(\gamma_{t z}(\tau)\right), \gamma_{t z}{ }^{0}\right) \Rightarrow \tau_{t z}=k_{t z} \cdot\left(\gamma_{t z}-\min \left(\max _{\tau \leq t}\left(\gamma_{t z}(\tau)\right), \gamma_{t z}{ }^{0}\right)\right)
\end{array}\right.
\end{aligned}
$$


Where $\mathrm{k}_{\mathrm{t}}$ and $\mathrm{k}_{\mathrm{tz}}$ are the stiffness values of debris and $\varepsilon_{\mathrm{t}}{ }^{0}$ and $\gamma_{\mathrm{tz}}{ }^{0}$ the maximum dimensionless sizes (size divided by width) of these debris respectively in the normal direction and in shear.

If the crack is assumed at $45^{\circ}$ in the (tz) plane these two stiffness values and debris sizes are equivalent and are assumed to be equal:

$$
k_{t}=k_{t z} ; \quad \varepsilon_{t}{ }^{0}=\gamma_{t z}{ }^{0}
$$

Consequently, only two material parameters are necessary to take into account the phenomenon of permanent indentation. These two parameters are difficult to relate to conventional material parameters measured in conventional tests and are directly determined using the reference impact test (cf. Sect. 4). Therefore this evaluation process limits the predictive character of this model, and in particular for the part linked to permanent indentation. Other works are actually in progress in order to evaluate these parameters with other and simpler experimental studies. It can be observed that these two parameters are the only ones of this model which are directly determined in the impact test: all other values are obtained from conventional experimental tests described in the literature [34-36, 39, 42, 44, 53].

This no-closure model integrated into the interface elements of matrix cracking makes it possible to obtain a deformed shape of the plate, not only during impact but also after impact, and a permanent indentation (Fig. 17b). It can be observed that this permanent indentation modeling has little effect on damage morphology, in particular delamination, matrix cracks and fiber failure, but principally the deformed shape, and that a modification of the values of the 2 associated parameters does not affect significantly simulated delamination.

\subsection{Conclusion of Modeling Principle}

A numerical model has been elaborated in order to simulate the different impact damage types developing during impact. The three current damage types: matrix cracking, delamination and fiber failures, are simulated. The modeling choices have been determined by the experimental investigations and the bibliography results.

Compared to existing models of the literature, the main originalities of the model in order to simulate the observed damage are:

- the use of interfaces for matrix cracking, with a failure criterion calculated in the neighboring volume elements,

- the use of volume elements with original formulation at the 8 integration points to control fiber failure based on fracture mechanics,

- the use of cohesive elements with a "plastic-like" behavior to simulate permanent indentation. 


\section{Experimental Validation Using a Reference Case}

\subsection{Introduction}

This section deals with experimental validation. An impact reference case has been chosen to evaluate the accuracy of the proposed model. As mentioned above, this step is not independent of the previous section and many comparisons of the numerical results and the experimental observations were required: this is the principle of the "test-calculation dialogue". However, these comparisons are not presented here for the purpose of simplicity.

Comparisons between experimental and numerical results were carefully performed using numerous refined experimental studies. The force-displacement and force-time curves were compared and show consistent agreement. The plate deformation numerically obtained after impact also compared well with micrographic cuts and with permanent deformation measured through image correlation. The numerically obtained delaminated interfaces were successfully compared with $\mathrm{C}$-scan on the impacted and non-impacted sides of the plate.

Finally the model is used to highlight some experimental results. It enabled us to highlight the formation of delamination of the first interface on the non-impacted side or to evaluate the distribution of dissipated energy during an experiment. This work is the second step of the "test-calculation dialogue", i.e. to better understand the experimental results in comparison to the numerical results.

\subsection{Experimental and Numerical Comparison}

The proposed model is used to simulate an experimental impact test, considered as a reference case, on $100 \times 150 \mathrm{~mm}^{2}$ laminate plate manufactured with T700/M21 UD carbon/epoxy composite. This plate, with stacking sequence $\left[0_{2}, 45_{2}, 90_{2},-45_{2}\right]_{\mathrm{S}}$ is simply supported by a $75 \times 125 \mathrm{~mm}^{2}$ window (AITM 00-10) and impacted at $25 \mathrm{~J}$ with a 16-mm diameter 2-kg impactor of (Fig. 15). Only the half plate is meshed due to symmetry considerations, the boundary conditions are imposed due to contact with a fixed rigid body and the impactor is assumed to be non-deformable (Fig. 15c). The mechanical characteristics of this material and the material parameters used in this model are summarized in Table 1.

Where $\mathrm{E}_{1}^{\mathrm{t}}\left(\mathrm{E}_{1}^{\mathrm{c}}\right)$ is the tension (compression) Young's modulus in the fiber direction, $\mathrm{E}_{\mathrm{t}}$ is the Young's modulus in transverse direction, $v_{\mathrm{lt}}$ is the Poisson's ratio, $\mathrm{G}_{\mathrm{lt}}$ is the shear modulus. As mentioned above, it can be observed that the $\varepsilon_{\mathrm{t}}{ }^{0}$ and $\mathrm{k}_{\mathrm{t}}$ are the only two parameters directly determined using the impact test: all other values come from conventional experimental tests in the literature [34-36, 39, $42,44,53]$.

The comparisons between experimental and numerical curves of impact force versus time and impactor displacement are illustrated in Fig. 16. A good correlation 
a

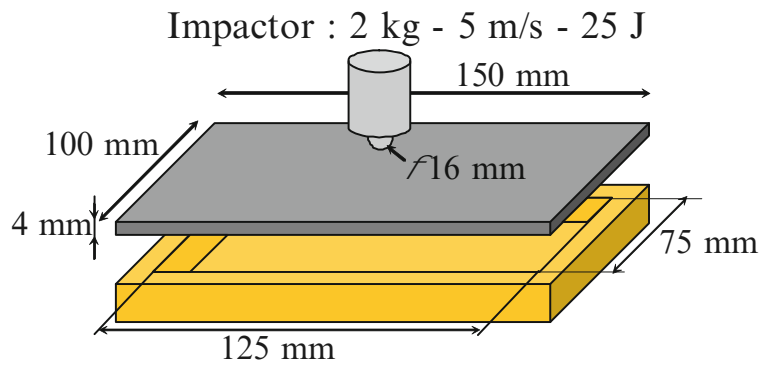

b

$\mathrm{T} 700 / \mathrm{M} 21\left[0_{2} / 45_{2} / 90_{2} /-45_{2}\right]_{\mathrm{S}}$ Impacted

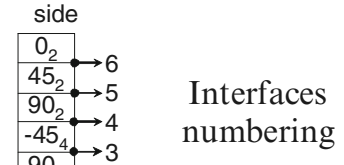

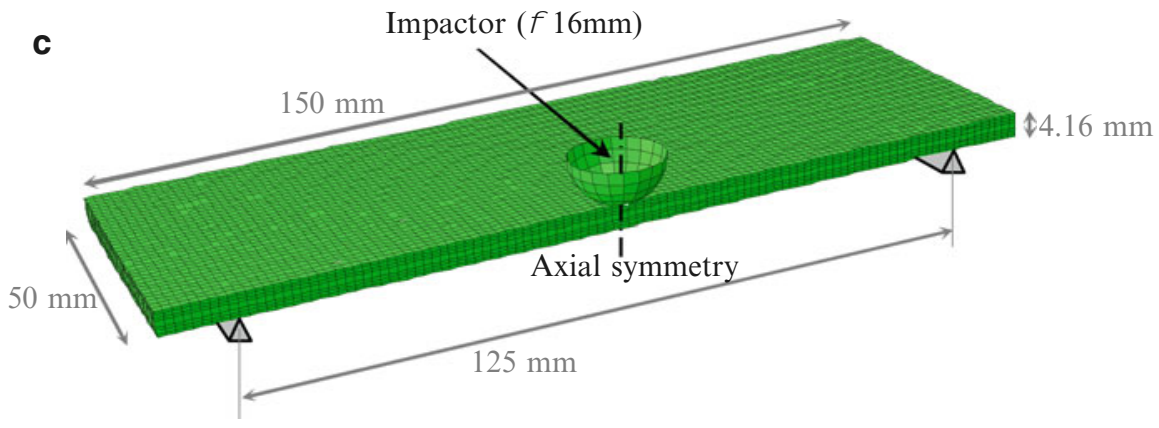

Fig. 15 Reference case: impact set up (a), draping sequence of the laminate (b) and finite element model $(\mathbf{c})$

a

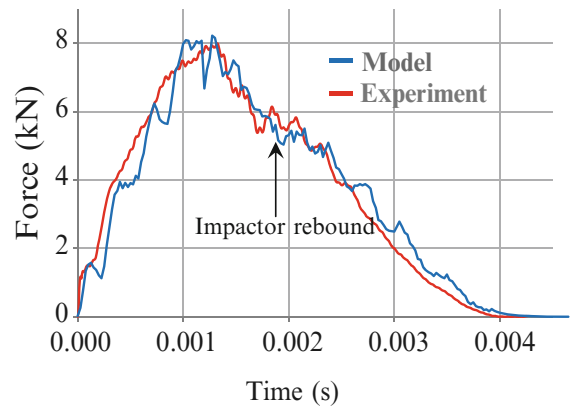

b

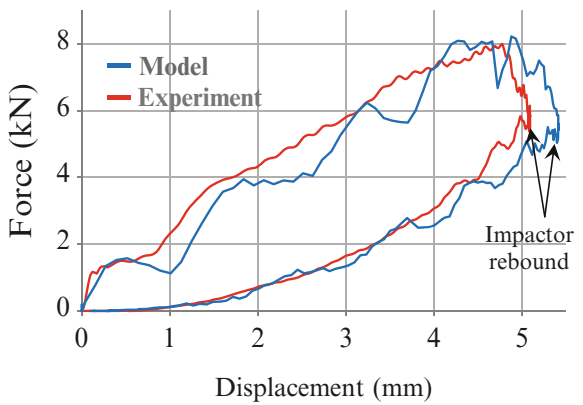

Fig. 16 Curves of force versus time (a) and displacement (b) obtained experimentally and numerically

is obtained between the experiment and model, demonstrating that the real impact damage is well account for in the numerical simulation. In particular the unloading is well simulated, while dissipated energy, corresponding to the area of the forcedisplacement curve, is correctly reproduced (Fig. 16b). The study of the dissipated 
energy during an impact test is of primary interest because detailed knowledge of these parameters enables us to classify the different kinds of damage. For example, to design a more tolerant structure, it may be useful to favor a more dissipative damage phenomenon, inducing less effect on residual strength. This classification of energy dissipated by the different damage phenomena will be discussed in more detail in the next paragraph.

In Fig. 17a, the deformed shape of the plate, obtained numerically, is represented in three cut planes $0^{\circ}, 45^{\circ}$ and $90^{\circ}$. Of course, each cut angle corresponds to the ply orientation, therefore in the $0^{\circ}, 45^{\circ}$ and $90^{\circ}$ cuts, the fiber directions of the $0^{\circ}, 45^{\circ}$ and $90^{\circ}$ plies, respectively, are approximately horizontal in the plane of the diagram. This deformed shape is obtained for $1.9 \mathrm{~ms}$, corresponding to the maximum displacement, about $6 \mathrm{~mm}$, reached during the $25 \mathrm{~J}$-impact. The displacement indicated in the figure is the z-displacement, corresponding to the normal direction. The displacement is maximum, corresponding also to the impactor stop, i.e. at null velocity before the rebound, but the force is decreased from its maximum value to about $1.3 \mathrm{~ms}$. It is due to the numerous fiber failures developing in the plate's central zone below the impactor, inducing a decrease of the impact force from 8 to $6 \mathrm{kN}$.

Some major damage is clearly visible in Fig. 17a. For example, the first ply, non-impacted side, is clearly broken in the transverse direction, which is visible in the $90^{\circ}$ cut. It can be also observed that, for an impact of $25 \mathrm{~J}$, this ply is not broken in the fiber direction. This transverse crack corresponds to the conventional crack observed after impact on the non-impacted side [14]. Delamination is also observable, in the very large opening of the first interface, non-impacted side, on the $0^{\circ}$ cut. The significant delamination of this interface is conventionally observed experimentally through C-Scan (Fig. 19). The central zone below the impactor is also severely damaged, as in the experiment (Fig. 12).

In Fig. 17b, the numerically obtained deformed shape of the plate after impact, is illustrated. This deformed shape is obtained for $4.3 \mathrm{~ms}$, corresponding to the end of the impact test. At this time, corresponding to the impactor rebound, a weak oscillation is still present in the plate, but we have verified that deformation of the plate is very close to the permanent deformation reached after a longer time. At this time, the impact damage is still visible, even if most of the interfaces are partially closed.

Of course, the deformed shape of the plate, obtained during the impact test (Fig. 17a) cannot be compared with experimental data because it is nearly impossible to stop impact during the test to perform micrographic cuts. But the deformed shape of the plate, obtained after impact (Fig. 17b) can be compared with micrographic cuts (Fig. 18): the plate is cut in $0^{\circ}, 45^{\circ}, 90^{\circ}$ planes and polished before examination with an optical microscope. Nevertheless, it is important to have the plate embedded in resin beforehand, to prevent the relaxation of the permanent indentation. In spite of this precaution, about $30 \%$ of the permanent indentation is relaxed during the specimen preparation. If we compare the experimental micrographic cuts with the numerical results, a good correlation is found. For example, the first interface, non-impacted side, remains open on the model, like in the experiment, 


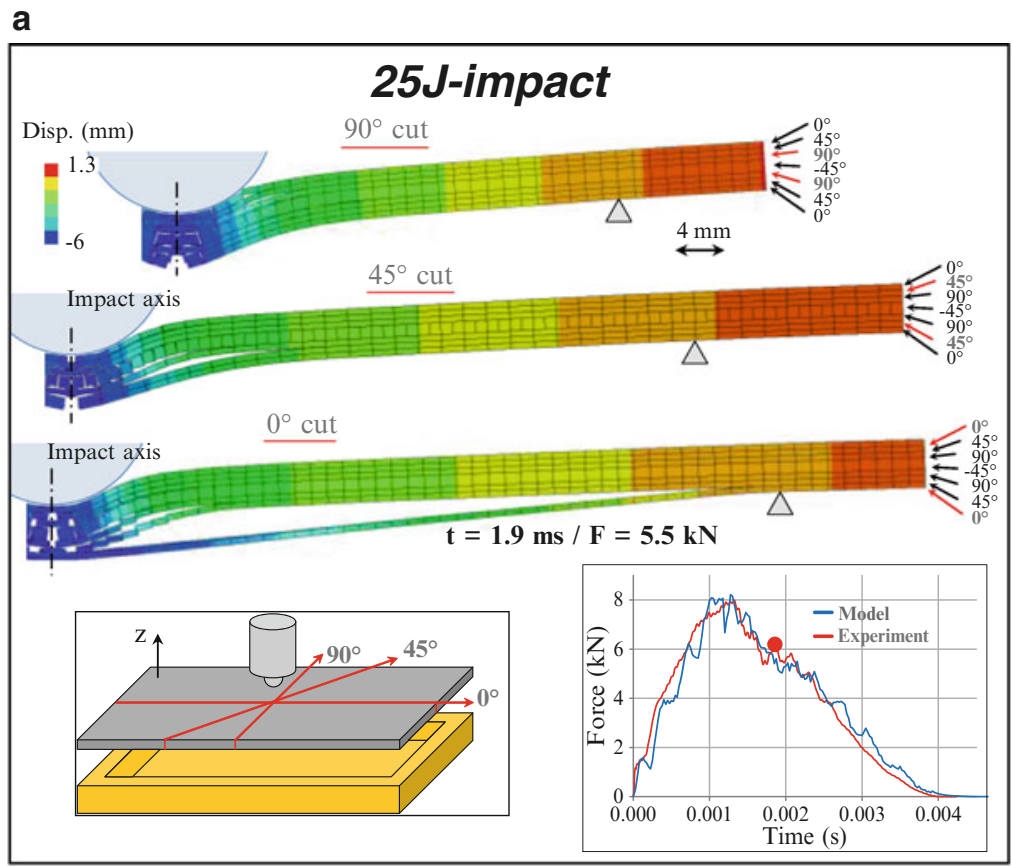

b

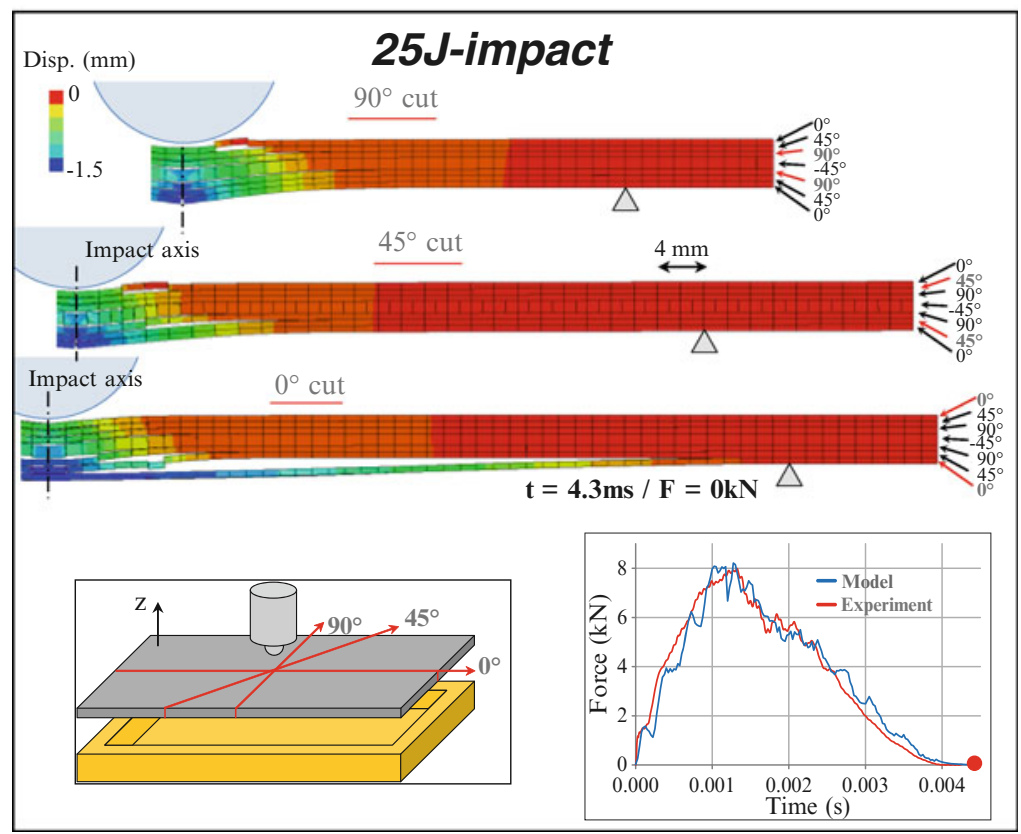

Fig. 17 Deformed mesh during 25 J-impact: (a) at maximum displacement - (b) after impact 

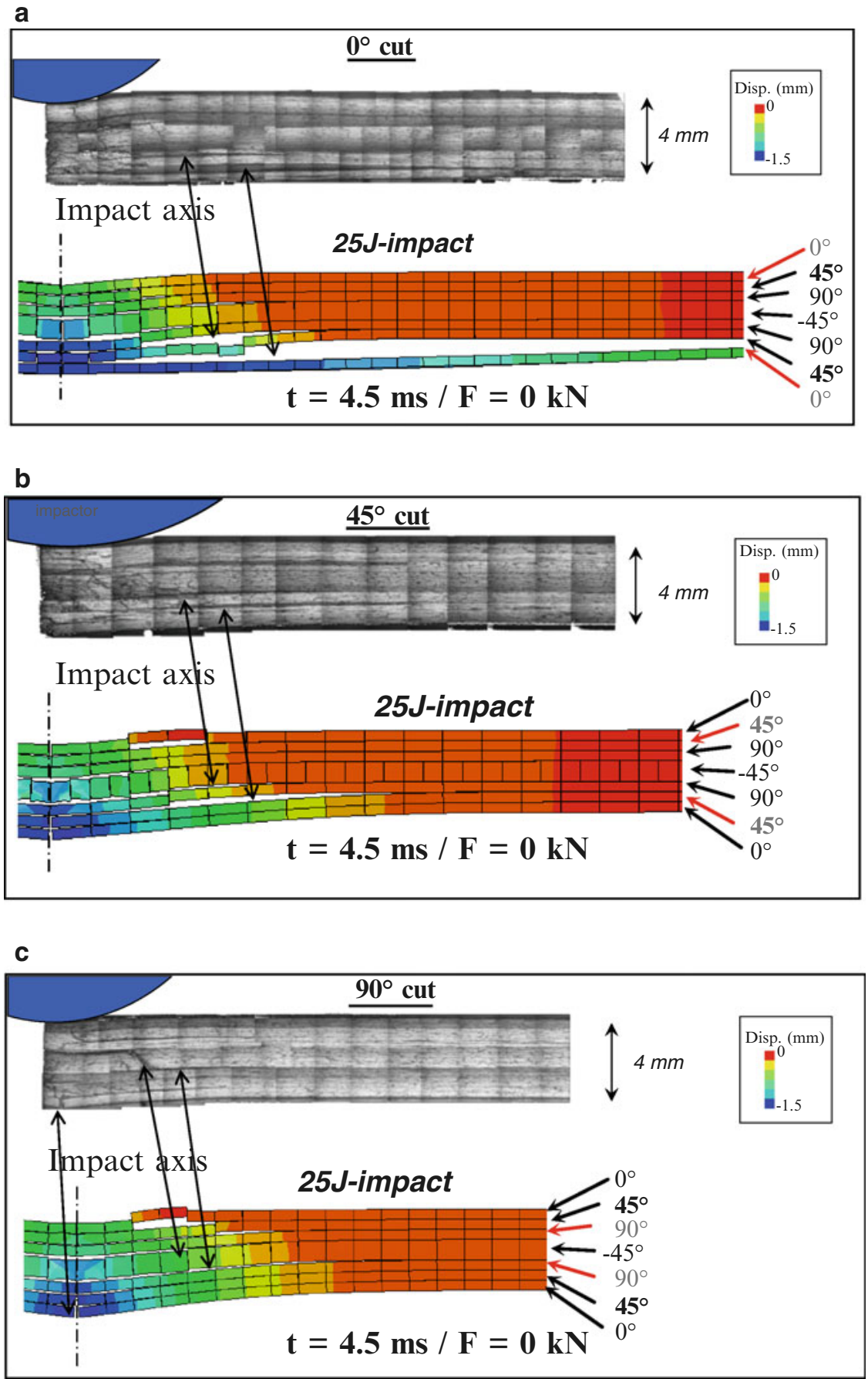

Fig. 18 Comparison between numerically and experimentally deformed shapes in the $0^{\circ}(\mathbf{a}), 45^{\circ}$ (b) and $90^{\circ}$ (c) planes 


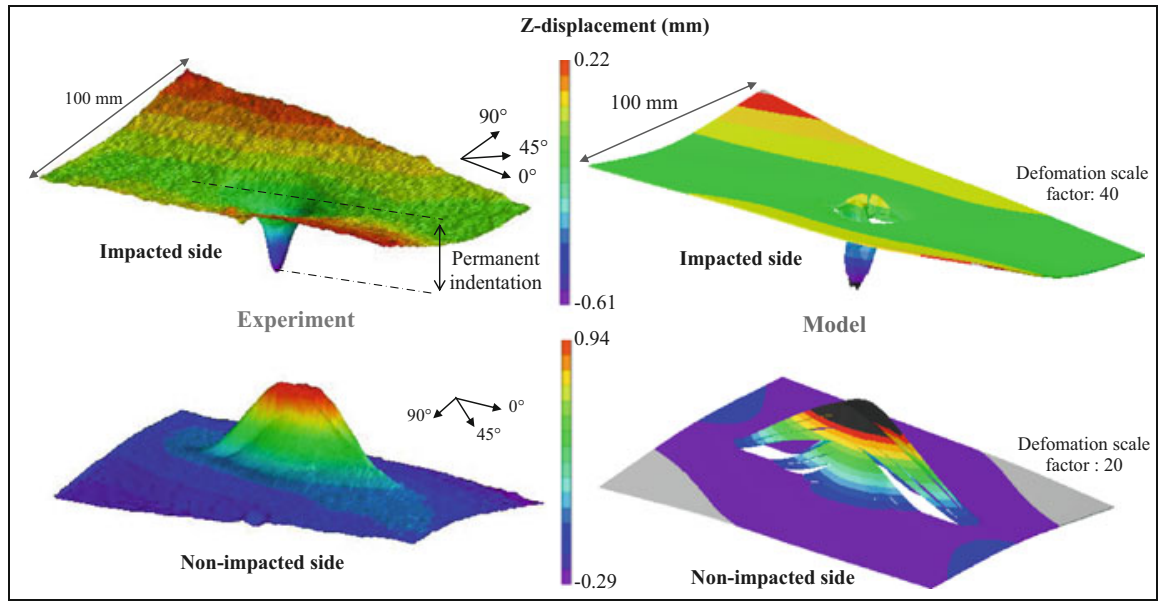

Fig. 19 Deformed plate after a 25 J-impact: experimental (a) and numerical (b) results

even if the opening is smaller in the experiment. Similar observations can be made on the $45^{\circ}$ and $90^{\circ}$ cuts. These differences can be explained partly by the relaxation of the experimental permanent indentation, which can be due to the cutting operation mentioned above, as well as due to the relaxation naturally observed after impact. Indeed a relaxation of about $30 \%$ is observed in the $48 \mathrm{~h}$ after impact [52] which is not taken into account by the model. Moreover the model of permanent indentation used is based on the debris blocking phenomenon and other phenomena such as resin "plasticity", and the relaxation of this "plasticity" are not taken into account.

Then the deformed plate resulting from the $25 \mathrm{~J}$-impact was plotted on the impacted and non-impacted sides (Fig. 19). The experimental results were obtained with Vic3D image correlations and the numerical results were obtained from the finite element calculations. The permanent indentation is clearly visible on the impacted side, but is difficult to define because the plate is twisted. We chose to define it by the distance between the lowest line of the twisted plate and the lowest point of the plate, i.e. at the impact point. In this case, a value of about $0.5 \mathrm{~mm}$ is obtained. The plate shape after impact was accurately simulated by the numerical model, and in particular, the general twisted shape of the plate was reproduced. The orientation of the twisted shape, in the diagonal the nearest to the $45^{\circ}$ ply, is due to the $\left[0_{2}, 45_{2}, 90_{2},-45_{2}\right]_{\mathrm{S}}$ draping sequence which induces a higher bending stiffness in this direction. In practical terms, the bending stiffness $D_{11}$ is about $3.6 \times$ $10^{5} \mathrm{~N} \cdot \mathrm{mm}$ in the $45^{\circ}$ direction compared to $1.8 \times 10^{5} \mathrm{~N} \cdot \mathrm{mm}$ in the $-45^{\circ}$ direction.

This twisted shape is also visible on the non-impacted side, in both the experimental and numerical results. Moreover the deformation of the impact point is larger than on the impacted side. For example, in the $\mathrm{Z}$ direction, the permanent indentation is about $1 \mathrm{~mm}$ compared to $0.5 \mathrm{~mm}$ on the impacted side. On the 

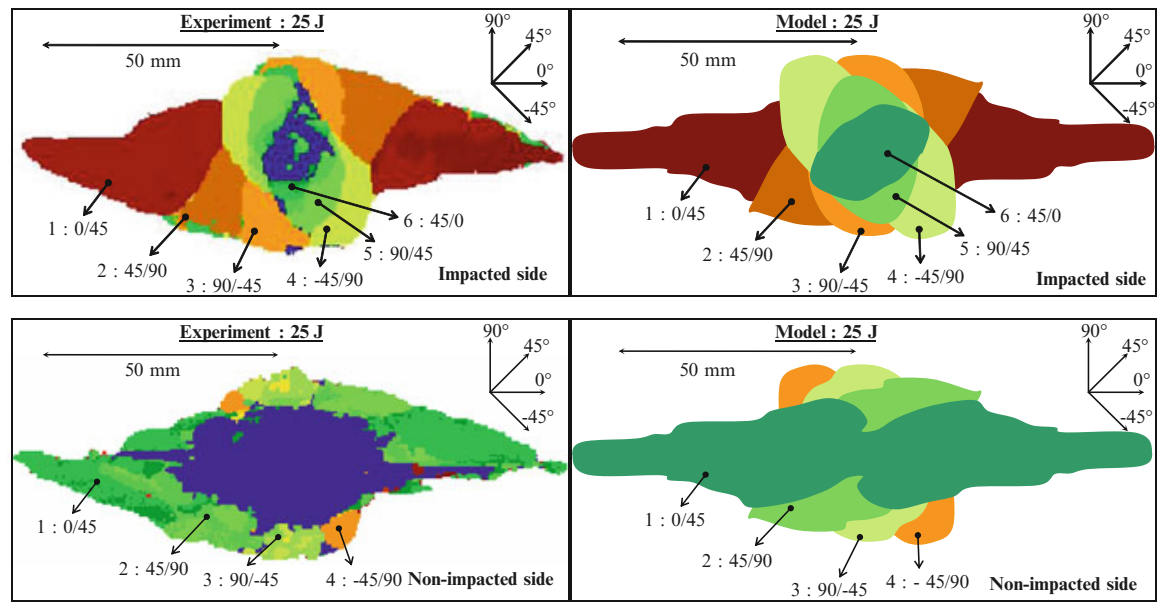

Fig. 20 Comparison between delaminated interfaces obtained experimentally (a) and numerically (b) from a 25J-impact test

non-impacted side, the terms of the impact point and the permanent indentation have been exaggerated to simplify the discussion. This higher indentation on the non-impacted side is due to the increased plate thickness in the impacted zone. This phenomenon is also visible in the micrographic cuts (Fig. 18), although it is lower, probably due to the cutting and polishing processes. It is generally simulated by the modeling but is amplified. Indeed, the black zone (Fig. 19b) represents Z-displacements above $0.94 \mathrm{~mm}$, the highest experimental value, and the grey zone represents Z-displacements below $-0.29 \mathrm{~mm}$, the lowest experimental value obtained. Moreover the experimental and numerical scales are set to a constant and were correlated to half scale (green color). Moreover it can be observed on the numerically obtained, non-impacted side of the deformed shape, openings exist between consecutive fiber strips (white colored zone). These opening are artificial and due to the large deformation scale factor.

The deformed zone is also higher in the $0^{\circ}$ plane of the non-impacted side, compared to the impacted side. This phenomenon is also generally simulated by modeling even if it is amplified.

In Fig. 20, delaminated interfaces obtained by calculation are compared to the experimentally obtained results, on the impacted and non-impacted sides. The accurate correlation between experimental and numerical results tends to confirm the relevance of the model, and in particular the model of interaction between inter and intra-laminar damage. As mentioned above, the shape of the delamination is closely linked to the interaction between matrix cracks and delamination $[4,6]$. In particular, the orientation of delamination with the fibers of the lower ply or the special shape of the first interface of the non-impacted side are well simulated. Moreover this first delamination shape seems to be nearly separated into two parts, 
as for the experimental results, although in the $\mathrm{C}$-scan, the extensive matrix cracking of the first ply of the non-impacted side makes this observation difficult. To confirm this result, a comparison was performed between the delamination of the first numerically obtained interface and the C-Scan examination performed on the nonimpacted side at different impact energy levels (Fig. 20).

This figure confirms the almost complete separation into two parts of this delamination which is clearly visible at $0.9 \mathrm{~ms}$. This fact, which is coherent with the literature $[1,6,15]$, is experimentally confirmed by the $17 \mathrm{~J}$ C-Scan, although this C-Scan involved a different test. In this figure (Fig. 21), the C-Scan was plotted at the point corresponding to $17 \mathrm{~J}$ of the $25 \mathrm{~J}$ test but is probably not the exact damage as shown at this point of the curve. Nevertheless the $17 \mathrm{~J}$-point attained with a $17 \mathrm{~J}$-impact or with the $17 \mathrm{~J}$-point of a $25 \mathrm{~J}$-impact are relatively close and the damage can be assumed to be equivalent. This delamination shape can be explained by the creation of a central conical shape at the beginning of the impact test below the impactor with high matrix cracking due to out-of-plane stresses $\left(\sigma_{\mathrm{tz}}\right.$ and $\left.\sigma_{\mathrm{lz}}\right)$. The delamination tends to be created on the boundaries of this cone and is not created just below the impactor (Fig. 23). This phenomenon can be highlighted by the illustration of the energy release rates in mode $\mathrm{I}, \mathrm{G}_{\mathrm{I}} / \mathrm{G}_{\mathrm{I}}{ }^{\mathrm{d}}$ and II, $\mathrm{G}_{\mathrm{II}} / \mathrm{G}_{\mathrm{II}}{ }^{\mathrm{d}}$, for each delaminated interface (Fig. 22).

It can be observed in this figure that mode II generally predominates, compared to mode I, except in a central zone around the impactor point. This zone can be assimilated to a conical central zone with its axis in the impact direction and with its higher diameter on the non-impacted side. It can be concluded that at the beginning of the impact test, the direct contact of the impactor with the laminate induces a conical shape with high matrix cracking due to out-of-plane stresses $\left(\tau_{t z}\right.$ and $\tau_{\mathrm{lz}}$ ). These matrix cracks tend to separate a central cone which induces a beginning of delamination with a high rate of mode I (Fig. 22a). This scenario is coherent with the literature $[1,6,15]$ which indicates a precursor role regarding the development of delamination and which assumes that the delamination development is principally related to mode I characteristics.

After this phase of delamination initiation, propagation of delamination is principally defined by mode II (Fig. 23b). This shearing fracture mode is due to high stresses in the lower ply of the interface in the fiber direction and explains the propagation direction of the delamination in the fiber direction of the lower ply.

Consequently, the "test-calculation dialogue approach" enabled us to define an appropriate model to accurately simulate an impact test and to take into account damage, such as matrix cracking, delamination, fiber failure or permanent indentation. Only two material parameters need to be identified on the reference impact test and the other ones are conventional material parameters. Nevertheless these two parameters only generate the simulated permanent indentation and scarcely modify delamination, matrix cracks or fiber failures. This model enabled us, in particular, to highlight formation of the delamination of the first interface on the non-impacted side and to explain its particular shape, partially separated into two parts. This result was determined by the creation of a central conical shape at the beginning of the 


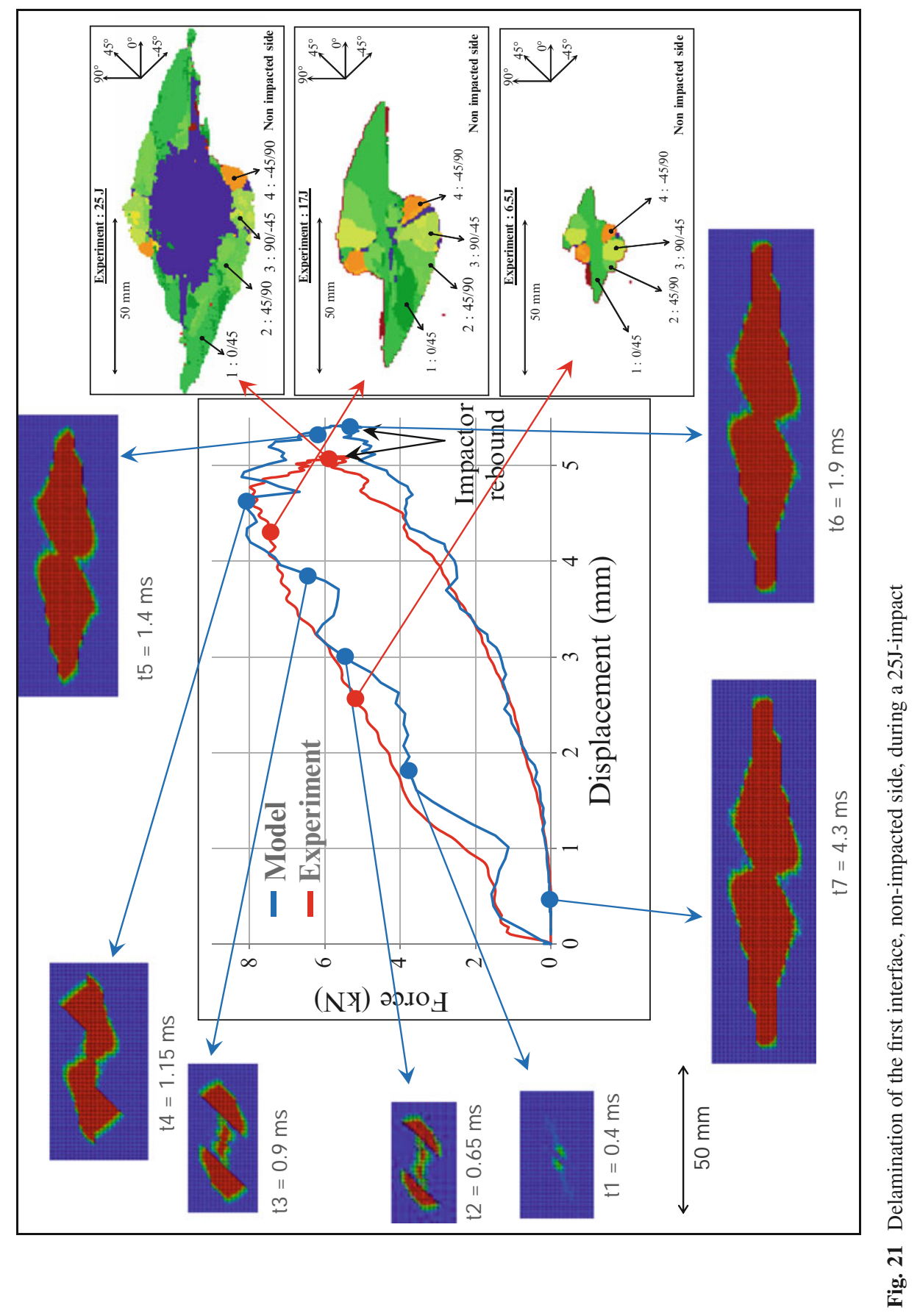


a

b

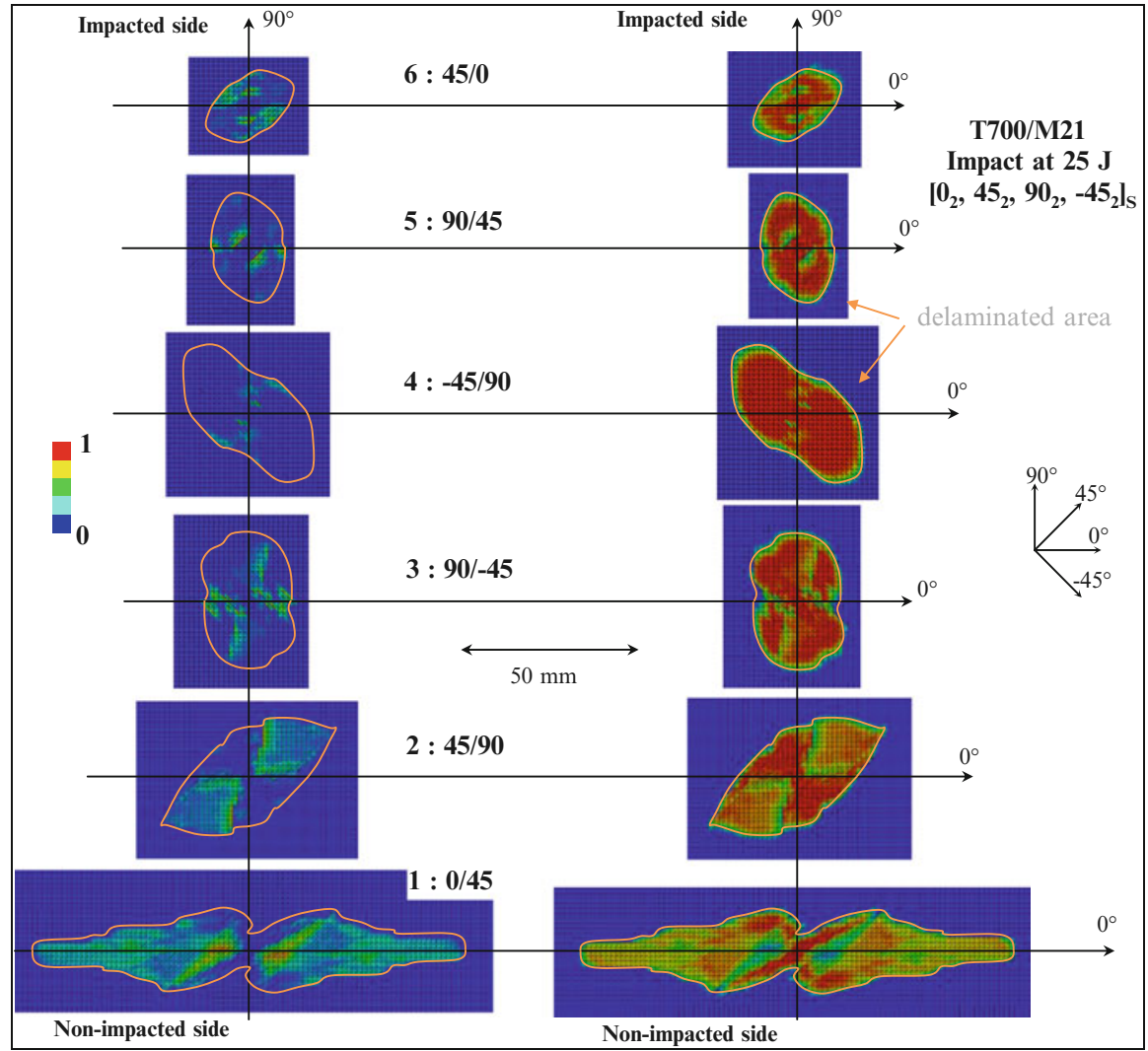

Fig. 22 Energy release rates in mode $\mathrm{I}, \mathrm{G}_{\mathrm{I}} / \mathrm{G}_{\mathrm{I}}^{\mathrm{d}}(\mathbf{a})$, and $\mathrm{II}, \mathrm{G}_{\mathrm{II}} / \mathrm{G}_{\mathrm{II}}{ }^{\mathrm{d}}(\mathbf{b})$

a

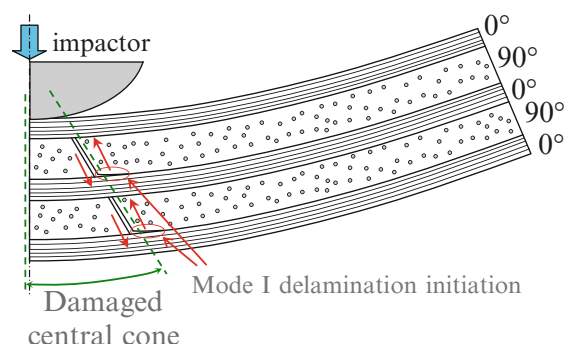

b

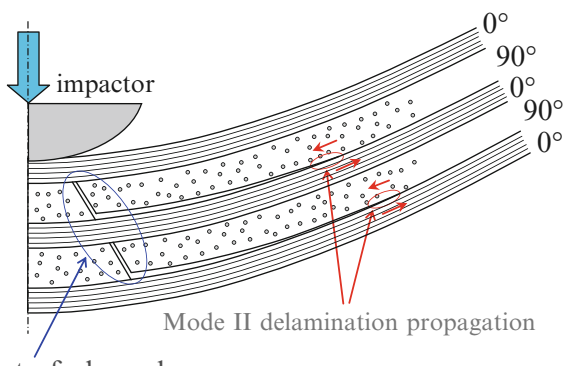

maxi out-of-plane shear

Fig. 23 Impact damage with creation of a severely damaged central conical shape: delamination initiation in mode I (a) and propagation in mode II (b) 


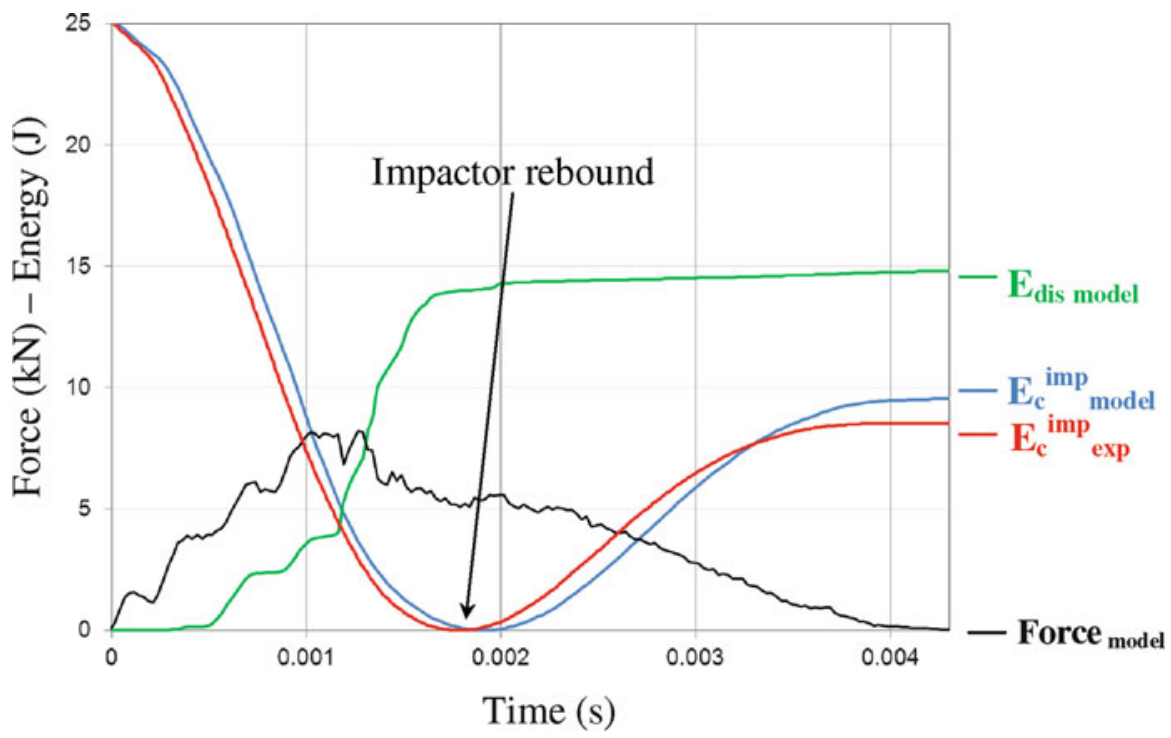

Fig. 24 Evolution of the dissipated energy during a 25J-impact

impact test, with high rate of opening fracture mode followed by propagation of delamination with high rate of shearing fracture mode.

\subsection{Dissipated Energy}

Afterwards, the model is used to evaluate the distribution of dissipated energy among the different damage phenomena. Figure 24 represents the evolution of the impactor kinetic energy, obtained numerically and experimentally.

The initial energy equals $25 \mathrm{~J}$, drops to $0 \mathrm{~J}$ when the impactor stops and attains about $9 \mathrm{~J}$ after impact, corresponding to the rebound. A relatively good correlation is obtained between the experiment and the model. The numerically obtained dissipated energy is also illustrated. This energy starts at $0 \mathrm{~J}$ and reaches about $15 \mathrm{~J}$ after the impact. This final value is approximately equal to the difference between initial and final values of the experimentally obtained impactor kinetic energy:

$$
E_{d i s} \approx E_{c}{ }^{i n i t}-E_{c}{ }^{\text {fin }} \approx 16.5 \mathrm{~J}
$$

Nevertheless in this approach, the final kinetic energy of the plate is disregarded and this hypothesis can be confirmed with numerical results:

$$
\text { at } t=4.3 \mathrm{~ms}, \quad E_{c}{ }^{\text {plate }} \approx 0.05 \mathrm{~J}
$$


The evolution of the numerically obtained force is also illustrated (Fig. 25). It can be observed that the dissipated energy greatly increases during loading until the impactor stops and is almost constant after that. In this figure, the impactor arrest corresponds to zero kinetic energy. But the model also enables us to determine the origin of this dissipation, which can be divided into four phases (Fig. 25):

- The viscous dissipated energy $\mathrm{E}_{\mathrm{visc}}$. This dissipation is due to the conventional coefficients of viscosity in order to stabilize the explicit calculation. This energy remains relatively low and the viscosity coefficients have been decreased as soon as possible to avoid numerical problems.

- The dissipated energy by indentation $\mathrm{E}_{\mathrm{ind}}$. However this energy is stored, rather than dissipated! Indeed the energy dissipated by matrix cracking is almost null, due to the chosen criterion without damping. This choice of non-dissipative failure criterion is adopted to avoid excessively mesh-size dependant with dissipated energy. Indeed the density of matrix cracking, which can be taken into account by the model, is totally dependent on the mesh. But this drawback should be less than expected because the presence of one matrix crack should discharge the neighboring cracks, which emphasizes the large cracks, rather than the small, diffuse matrix cracks. In order to be more precise, the diffuse matrix cracking could be integrated by adding a continuum damage factor to the volume elements of the plies, as is usually done in the literature [19, 24]. However in this way, it is difficult to experimentally separate the diffusive matrix cracks from the large ones, i.e. those propagating through the entire ply thickness, and significantly influencing delamination. In this study, only the large matrix cracks are taken into account in order to avoid a more complex model, and as mentioned above, their dissipated energy is disregarded. In reality, it is difficult to evaluate what part of the dissipated energy comes from matrix cracking. Moreover a part of this dissipated energy should be included in the delamination value. Indeed the critical energy release rate of delamination is obtained from experimental tests, such as the double cantilever beam test, the mixed mode flexure test or the end notched flexure test which induce some matrix cracks [34, 35]. It is particularly true for multidirectional interfaces, i.e. when the angle between the two plies of the studied interface does not equal $0^{\circ}$ (Fig. 26). And a part of this supplementary dissipated energy of a multidirectional interface should be due to supplementary matrix cracking; another part of this extra energy being due to bridging effects [34]. Consequently, $\mathrm{E}_{\mathrm{ind}}$ is not energy dissipated in the matrix cracks but energy stored in the permanent indentation phenomenon: about half of this energy is stored in the matrix cracking interfaces, which are impeded from closing (Eq. 12), and half is stored in the volume elements which are always constrained after impact due to this non-closure phenomenon. Nevertheless this stored energy remains low compared to the energy dissipated by fiber failure and delamination.

- The energy dissipated by delamination $\mathrm{E}_{\mathrm{del}}$. This dissipation is due to the softening interface elements used to simulate delamination (Fig. 11) and is directly linked to the delaminated area. 


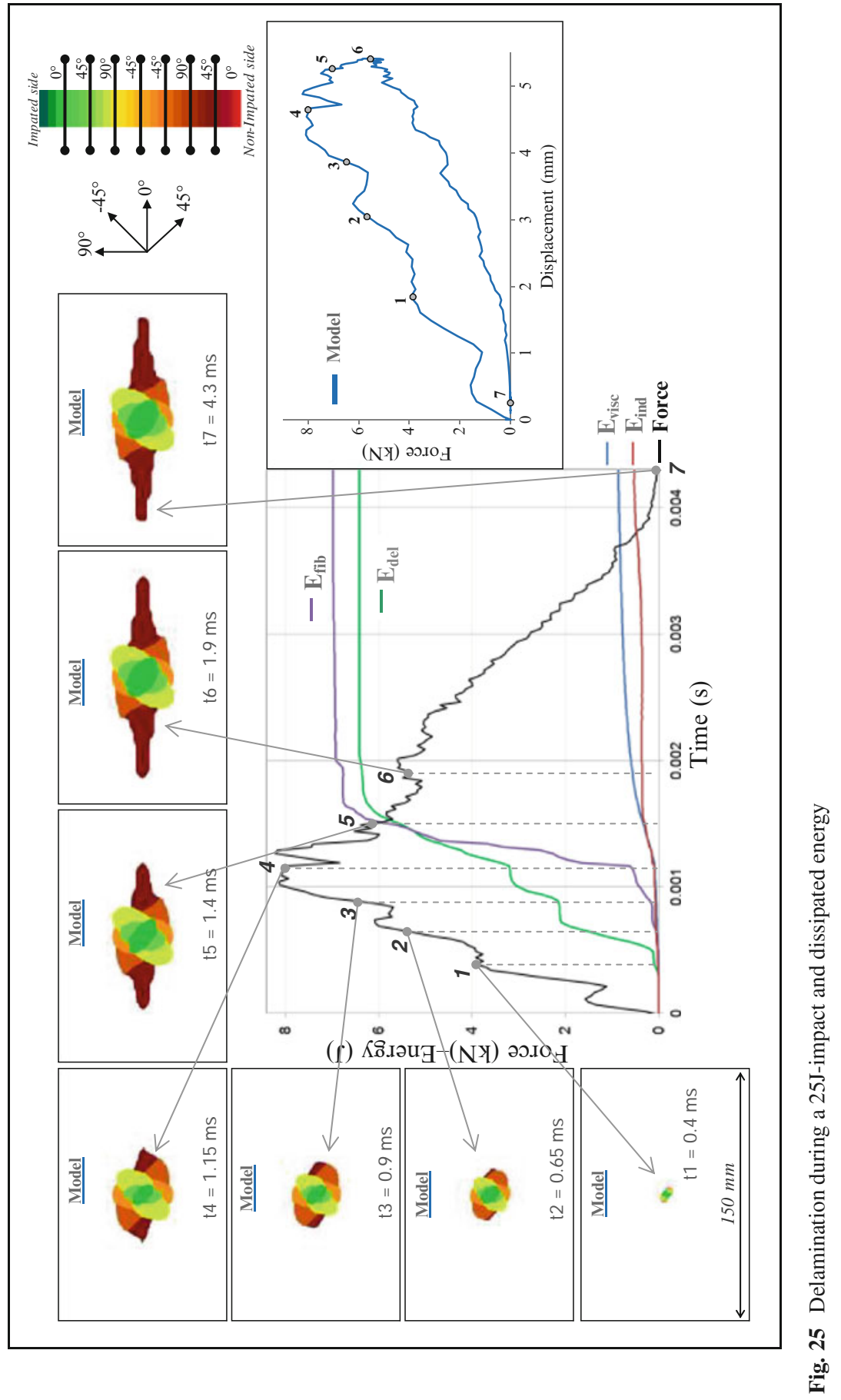




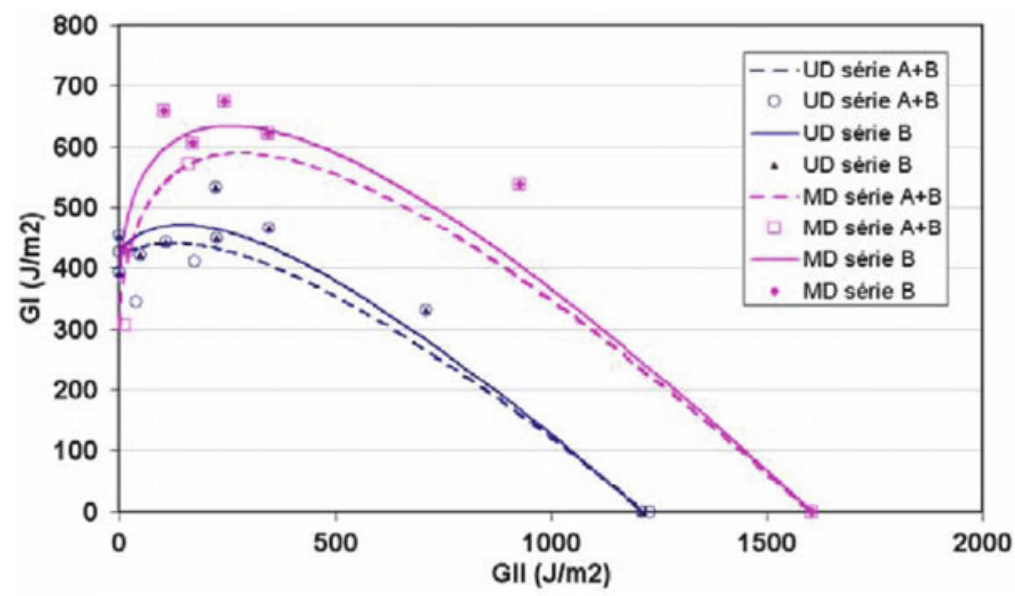

Fig. 26 Mixed mode of critical energy release rate for unidirectional (UD) and multidirectional (MD) interfaces [34]

- The energy dissipated by fiber failure $\mathrm{E}_{\mathrm{fib}}$. This dissipation is due to the softening behavior law of volume elements used to simulate fiber failure (Fig. 8) and is directly linked to the volume of broken fibers.

The origin of this dissipated energy is particularly interesting and highlights the damage scenario developing during impact. The first step is until point 1 (Fig. 25), no important damage is observed, only some matrix cracks, and the structure behavior is linear overall, with conventional oscillations due to dynamic loading. At point 1 , the delamination begins to appear and increases with the impact force until point 4. Of course the greater the impact force, is the greater the delaminated area. A small decrease in plate stiffness is observed at point 1 due to this delamination. Before point 4, only a few fiber failures are observed and are not significant in the overall behavior of the structure. From point 4 and until point 6 , the impact force decreases significantly due to fiber failure and the dissipated energy due to these fiber failures increases simultaneously. The effect of these fiber failures is clearly seen in the plate stiffness value. It is also during this step, between points 4 and 6 , that the indentation energy increases, due to the blocking phenomenon of debris in the matrix cracking interfaces. Finally between points 6 and 7, no significant additional damage is observed.

At the end of the impact, the dissipated energy is divided into two nearly equal parts: delamination and fiber failure. Although it is due to random chance, since these two phenomena evolve very differently, and this conclusion could be different for another impact energy level.

Nevertheless these numerical results concerning the distribution of dissipated energy should be carefully taken into account due to the hypotheses adopted. For example, the dissipated energy in matrix cracking is not directly taken into account, 
nevertheless part of this energy may be included in the delamination energy, more work is necessary to better understand the consequences of this hypothesis. For example, the dissipated energy due to fiber failure is only considered in the opening fracture mode (I) under tension stresses. This seems to be correct for this type of impact but with other conditions, shearing (II) and tearing (III) fracture modes, or fracture due to compression stresses, could be important (cf. Sect. 5). Finally, the stored energy due to permanent indentation may not be estimated accurately. Indeed the adopted model attributes greater importance to the blocking phenomenon of debris in matrix cracking on this indentation, and does not take into account the "plasticity" of the resin. Therefore, the corresponding stored and dissipated energy of this "plasticity" are not taken into account and should modify the dissipated energy distribution. Consequently, a model only represents a more complex phenomenon, therefore the use of this particular model to represent energy distribution should be carefully considered due to the difficulty of comparisons with the experimental results.

Consequently, this model's accuracy makes it possible to determine the distribution of dissipated energy among the different types of impact damage. In this $25 \mathrm{~J}$-impact, the dissipated energy is divided into two nearly equal parts, the first one due to delamination and the other one due to fiber failure. Nevertheless these two types of dissipated energy develop quite differently: the delamination phenomenon begins first and increases slowly, while the fiber failure phenomenon begins later and increases rapidly. These developments can also be correlated with delamination and highlight the scenario of impact damage formation. These energy dissipation developments are very interesting, in particular because they are almost impossible to obtain experimentally.

\subsection{Conclusion of Experimental Validation}

The modeling of an impact reference case has made it possible to demonstrate the accuracy of the proposed model. The impact curves, such as force-displacement or force-time curves, the delaminated interfaces or the permanent deformation of the plate after impact were correctly simulated. This comparison was performed using numerous refined experimental studies and enables us to have relative confidence in this model.

Therefore the model can be used to more deeply analyze the behavior of materials during impact, such as the fracture modes involved in delamination or the distribution of dissipated energy. The most original aspect concerns the separation of the overall dissipated energy among the different damage types. For the reference impact case, the dissipated energy is divided into two equal parts, the first one due to delamination and the other one due to fiber failure. Nevertheless these two types of energy dissipate very differently and could give different results for other types of impact energy. 


\section{Effect of Impact Conditions}

\subsection{Introduction}

This section deals with numerical validation. Different experimental impact tests have been simulated with different impact configurations and compared to experimental results.

The first test parameter is the impact energy used to set up the damage scenario during impact. Afterwards the effect of boundary conditions is studied and reveals some of the model's limits. Then the stacking sequence is changed to highlight other damage scenarios during impact. Finally the effect of impact velocity is studied in an attempt to separate the inertial effects from the strain rate effects.

These results show that engaging a "test-calculation dialogue" related to these supplementary experiments could contribute to enlarging the domain validity of the modeling. This work is currently in progress.

\subsection{Effect of Impact Energy}

The first effect studied is that of impact energy. Some of the impact tests have been performed, although only four particular impact tests are presented in detail. These four impact tests at $6.5,17,25$ and $30 \mathrm{~J}$ have been simulated and compared to experiments. The correlation between delaminated interfaces and corresponding force-displacement curves is relatively close for the different types of impact energy (Fig. 27).

In this figure, due to an experimental problem the $17 \mathrm{~J}$ curve is not represented. This relatively good correlation is also visible on the curves of the delamination area and indentation versus impact energy (Fig. 28). In these figures, a supplementary impact test at $1.6 \mathrm{~J}$ is represented, but it did not induce a delaminated area, either experimentally or in simulation.

The model is the least accurate for $30 \mathrm{~J}$ and overestimates the damage. This could be due to the fiber failure model which could not correctly take into account the high impact damage near plate perforation, and other considerations should be modeled, such as shearing fracture mode of fibers, or removal of volume elements after fiber failure.

It is interesting to notice in the Fig. 28b, the strong increase of indentation for an impact of about $17 \mathrm{~J}$. Based on the dissipated energy curve (Fig. 25), this phenomenon can be attributed to the apparition of fiber failures: when fiber failures appear, damage in the central zone below the impactor develops rapidly, inducing opening of matrix cracks, creation of debris blocking and increase of permanent indentation. This phenomenon is coherent with the experimental studies of Chen et al. [47] showing that permanent indentation increases suddenly when the first fiber failures are observed. 


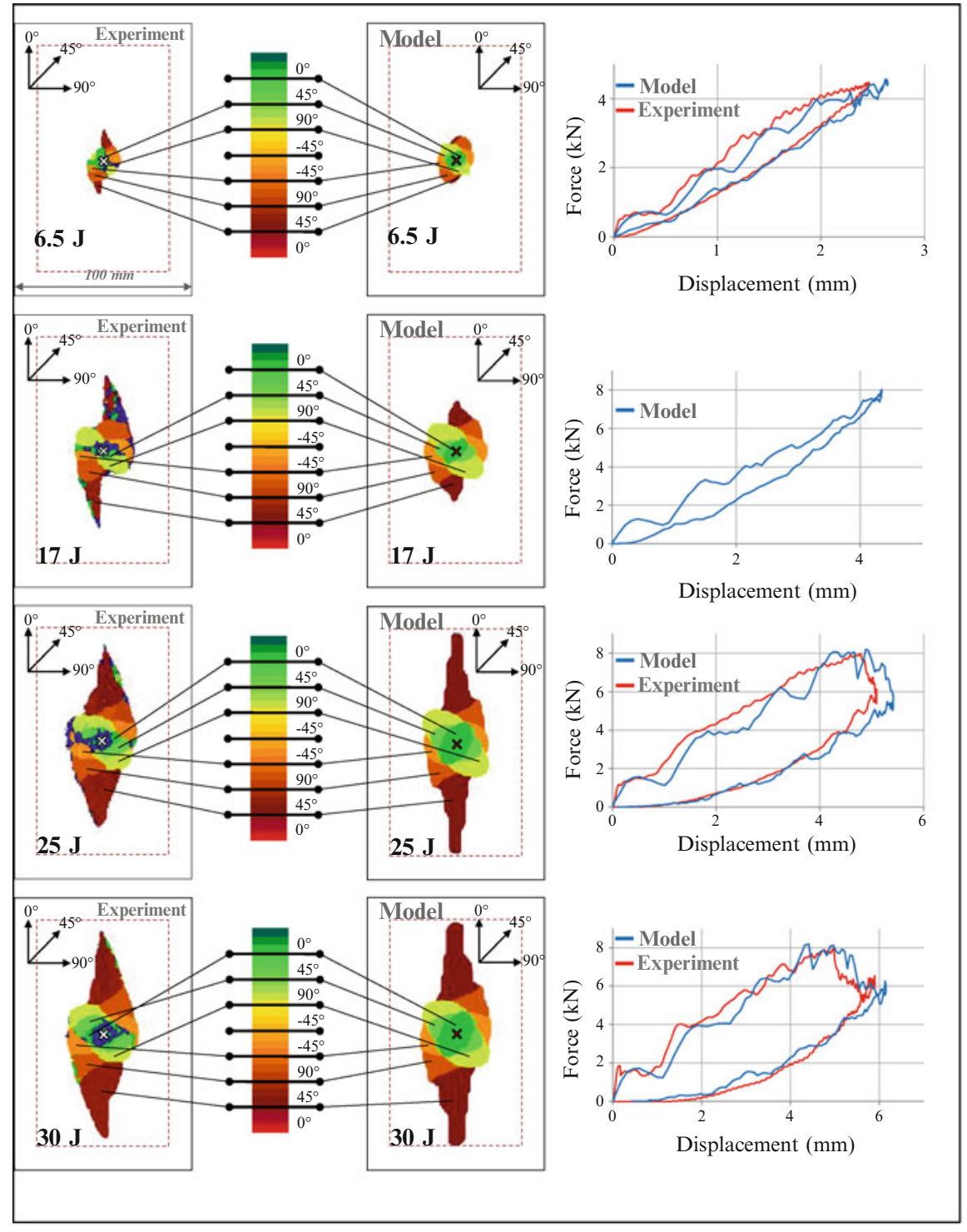

Fig. 27 Comparison between delaminated interfaces obtained experimentally and numerically for different types of impact energy

This phenomenon is interesting because it could make it possible to design composite structures more easily indented during impact by favoring fiber failure. Nevertheless, the effect of these fiber failures on compression after the impact test should be studied because it may play a precursor role on the final fracture under compression loads. 
a

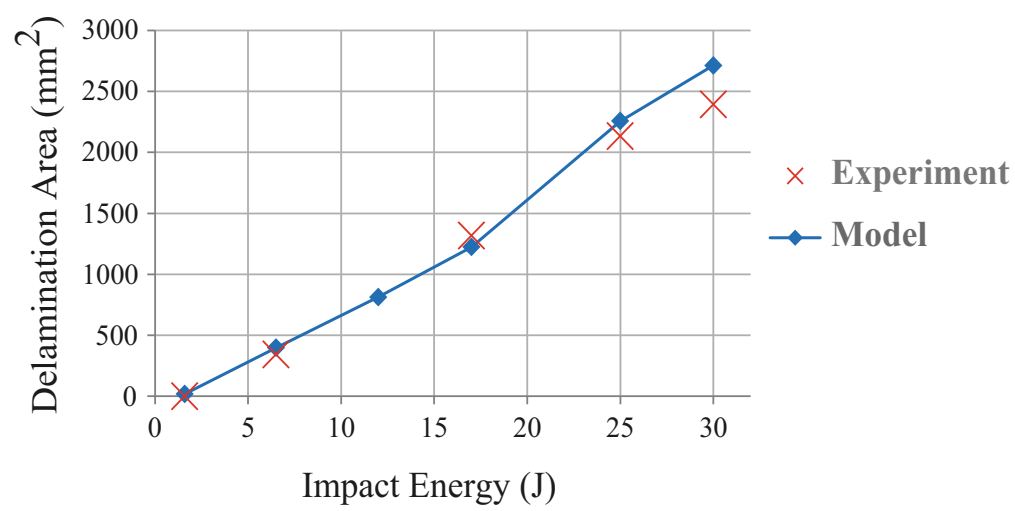

b

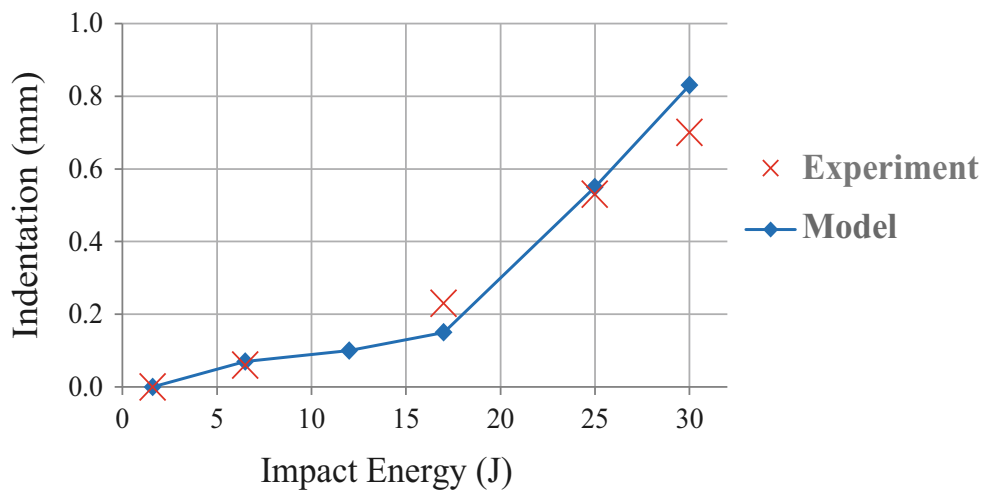

Fig. 28 Curves of delamination area (a) and permanent indentation (b) versus impact energy obtained experimentally and numerically

Consequently, the study of impact energy effects enables us to confirm the validity of this model with different damage sizes, and highlights the experimental results. For example, it enabled us to link the change in development of permanent indentation, versus impact energy, with the appearance of fiber failures which induce the large opening of a damaged central cone under the impactor and the creation of debris blocking.

\subsection{Effect of Boundary Conditions}

In order to evaluate the reliability of the model, the position of the impact point was moved from the centre (reference case) to a corner (Fig. 29), the plate being supported on the four edges as before (Fig. 15). 

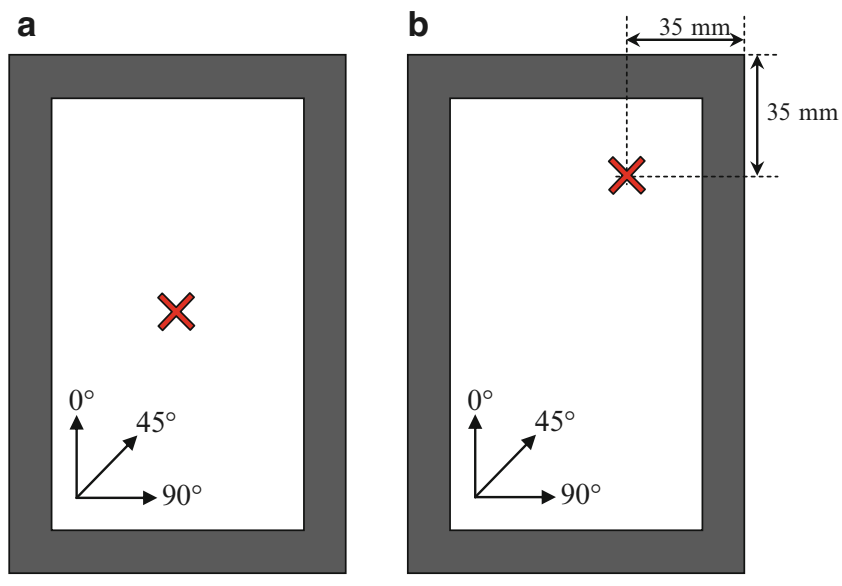

Fig. 29 Position of the impact point: reference case (a) and corner impact case (b)

This corner impact case enabled us to obtain different impact test boundary conditions with the same plate and experimental set up. This type of boundary condition is also interesting because it could be representative of an impact near a stiffener of a composite panel [17]. Indeed in a real composite structure, the stiffeners locally increase the structural stiffness and modify impact damage. And in order to validate a composite structure with impact damage tolerance, it is necessary to evaluate its residual strength whatever the impact location.

Finally, this case also enables us to obtain a non-symmetric situation, such as the delaminated areas (Fig. 30). This corner impact test was performed at $17 \mathrm{~J}$ and $25 \mathrm{~J}$ and is compared to the centre impact test at $25 \mathrm{~J}$.

The comparison between the two experimental $25 \mathrm{~J}$-impact tests shows that the maximum forces are similar at about $8 \mathrm{kN}$ but the corresponding displacement is less for the corner impact test, at $3.5 \mathrm{~mm}$ versus $4.8 \mathrm{~mm}$ for the reference case. This is explained by the higher stiffness of the corner impact test due to the proximity of the impact point with the boundary condition. This higher stiffness is generally well reproduced by the model, although the stiffness decrease at $1.2 \mathrm{~mm}$, due to delamination onset, is numerically overestimated. Moreover the load drop after the maximum load is delayed on the calculation compared to the experiment. This load drop can be attributed to fiber failure and an observation of the plate after impact shows fiber failures of the first ply on the non-impacted side (Fig. 31). This failure is observed only on the boundary condition and could be due to out-of-plane shear failure.

This type of fiber failure is not taken into account in the model and the numerically estimated load drop is due to tension fiber failure just under the impactor. Therefore, the model should be improved to be able to take into account this type of fiber failure due to out-of-plane shear stresses in order tobetter estimate 


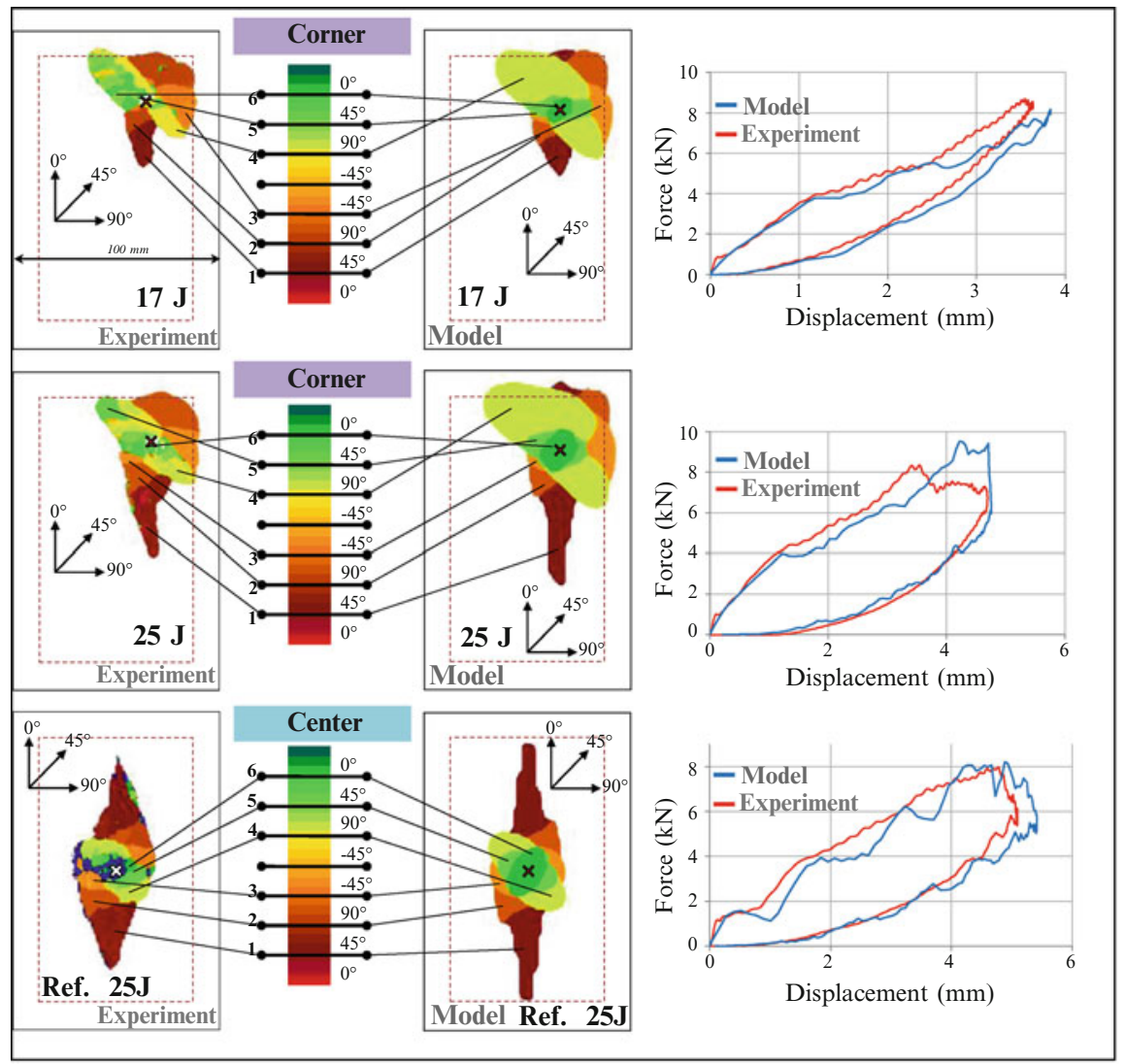

Fig. 30 Delaminated areas and force-displacement curves for corner impact case at $17 \mathrm{~J}$ and $25 \mathrm{~J}$ and reference case at $25 \mathrm{~J}$

the load drop of this type of impact test. Of course this type of modeling of fiber failure exists in the literature [38, 40-42] and should be adapted to the present modeling.

In general the delaminated interfaces are accurately estimated by the model except at the top left of the impact point where the model forecasts the delamination of the fourth interface and the experiment shows mixed delamination of the fourth, fifth and sixth interfaces. This discrepancy could be due to the shear fiber failures mentioned above. In order to validate this hypothesis, a corner impact test at $17 \mathrm{~J}$ was performed. In this case, no fiber failure was observed non-impacted side and indeed a good correlation was obtained between the experiment and the model for the force-displacement curve. Again, the general delamination shapes are well simulated except at the top left of the impact point where the model does not forecast the delamination of the sixth interface. Moreover at this location, in observing the 
Fig. 31 Non-impacted side of the plate after $25 \mathrm{~J}$ corner impact test

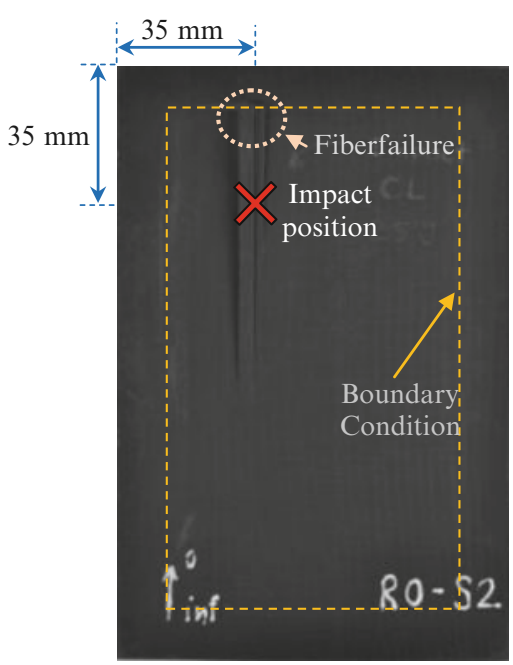

Non-Impacted side

experiments at 17 and $25 \mathrm{~J}$, delamination jumps are seen between the first three interfaces on the impacted side. The reasons for this non-standard delamination are not very clear and more experimental studies are necessary to better explain it.

To conclude, modification of the impact point position showed that it is necessary to take into account the fiber failure under shearing and tearing fracture modes. Nevertheless modification of the impact point position also demonstrated the relatively accurate performance of the model with non-standard boundary conditions. Moreover this type of test is necessary to validate this model before it can be used to design a real composite structure, subject to impact at all points, and in particular near stiffeners.

\subsection{Effect of Stacking Sequence}

In order to evaluate the model's validity domain, laminated plates with different stacking sequences were impacted (Fig. 32). Three stacking sequences were studied and each sequence was tested with $0^{\circ}$ ply both longitudinally and transversally. This resulted in 6 stacking sequences, but required the manufacture of only 3 plates, by varying the cuts. In order to facilitate the presentation, the two plates, rotated at $90^{\circ}$ are named with the same letter (Table 2, i.e. C1/C2, D1/D2 ...).

On Fig. 32, the delaminated areas and force-displacement curves, obtained numerically and experimentally, are illustrated. The correlations between the experiment and the model are acceptable. In practical terms, the shape of delaminated areas is qualitatively well simulated, but the projected delaminated areas are still overestimated (Fig. 33). 

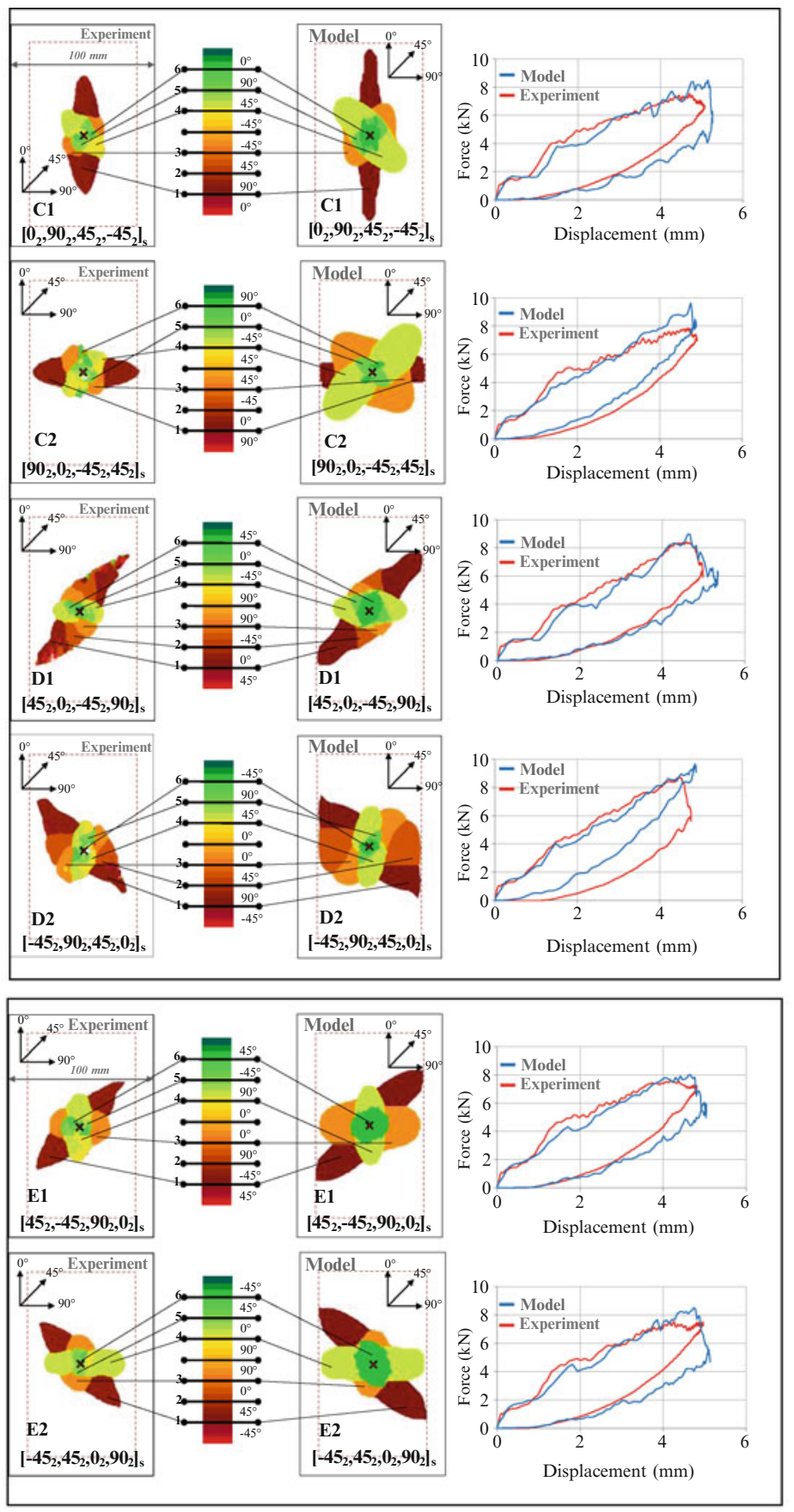

Fig. 32 Effect of stacking sequence on delaminated areas and force-displacement curves of $25 \mathrm{~J}$ impact tests 
Table 2 The different stacking sequences studied

\begin{tabular}{lll}
\hline Name & Stacking sequence & Remark \\
\hline Ref & {$\left[0_{2}, 45_{2}, 90_{2},-45_{2}\right]_{\mathrm{S}}$} & \\
C1 & {$\left[0_{2}, 90_{2}, 45_{2},-45_{2}\right]_{\mathrm{S}}$} & $90^{\circ}$-rotation of C2 \\
C2 & {$\left[90_{2}, 0_{2},-45_{2}, 45_{2}\right]_{\mathrm{S}}$} & $90^{\circ}$-rotation of C1 \\
D1 & {$\left[45_{2}, 0_{2},-45_{2}, 90_{2}\right]_{\mathrm{S}}$} & $90^{\circ}$-rotation of D2 \\
D2 & {$\left[-45_{2}, 90_{2}, 45_{2}, 0_{2}\right]_{\mathrm{S}}$} & $90^{\circ}$-rotation of D1 \\
E1 & {$\left[45_{2},-45_{2}, 90_{2}, 0_{2}\right]_{\mathrm{S}}$} & $90^{\circ}$-rotation of E2 \\
E2 & {$\left[-45_{2}, 45_{2}, 0_{2}, 90_{2}\right]_{\mathrm{S}}$} & $90^{\circ}$-rotation of E1 \\
\hline
\end{tabular}

节

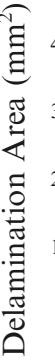

4000
2000
1000

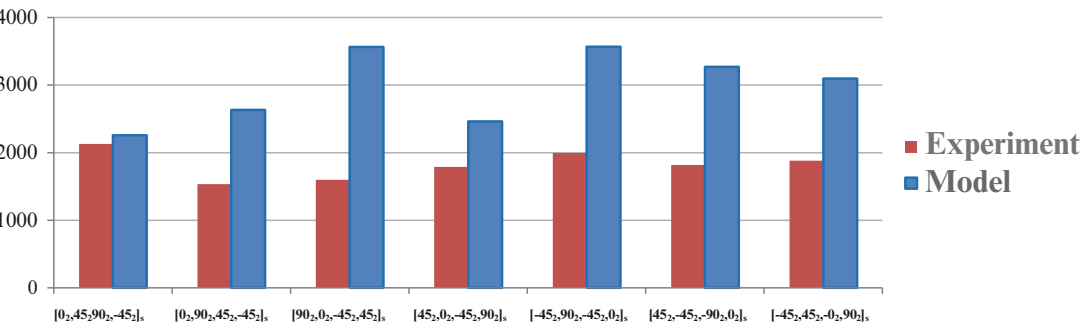

Ref.

C1

C2

D1

D2

E1

E2

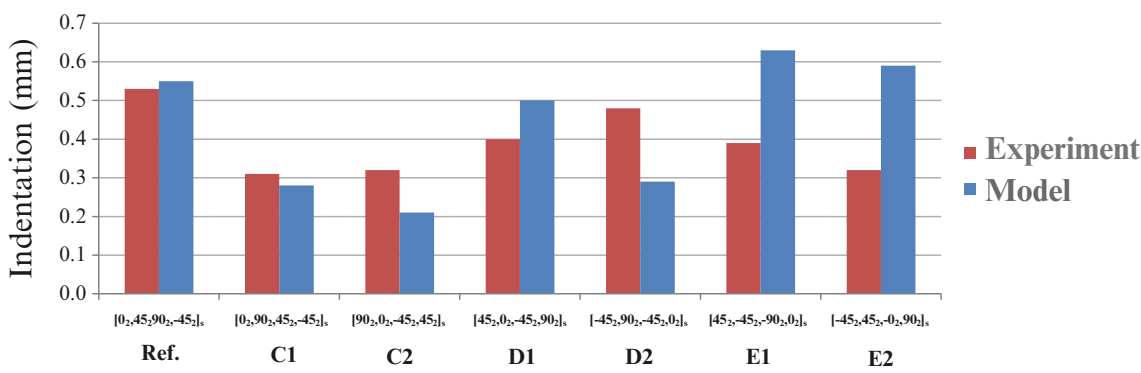

Fig. 33 Effect of stacking sequence on delaminated areas and indentation

This confirms that the model accurately takes into account the phenomenon of impact damage formation and in particular the interaction between matrix cracks and delamination but quantitative discrepancies of the projected delaminated areas highlight some problems. These discrepancies are also observed on the forcedisplacement curves. The D2 case is particularly interesting. In general, the model accurately simulates the delamination shapes, but the areas are highly overestimated and propagation is even arrested by the boundary conditions. This phenomenon is also observed on the force-displacement curve where a strong load drop is experimentally obtained but is not simulated. This load drop could be due to fiber failures which are not taken into account by the model, for example compression or shearing fractures. This hypothesis is confirmed by the delamination simulated before this experimental load drop (Fig. 34). 


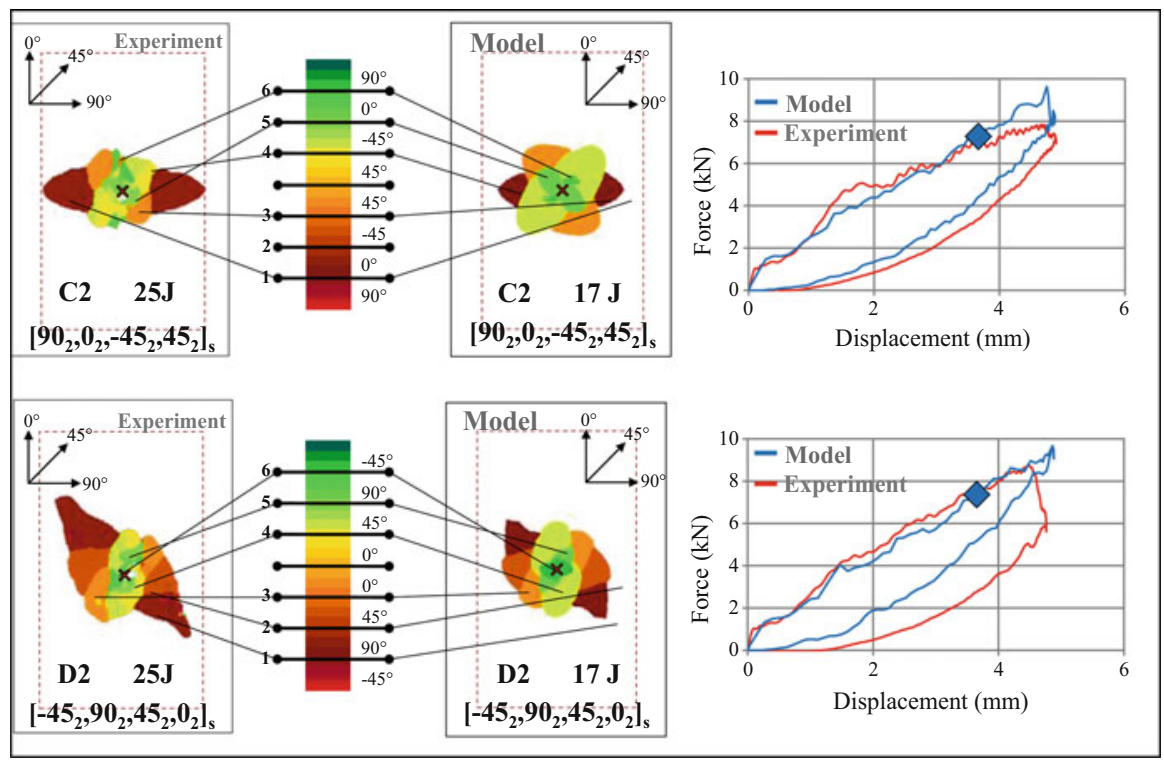

Fig. 34 Delaminated areas at $17 \mathrm{~J}$ during a $25 \mathrm{~J}$-impact simulation (C2 and D2 cases)

In Fig. 34, delamination calculated for 3.8 mm-displacement (17 J) during a 25 J-impact simulation are illustrated and show a good correlation with experimental results, although the delamination of the first interface, on the non-impacted side is underestimated. This good match between experiment and modeling confirms that discrepancies at $25 \mathrm{~J}$-impact could be due to the end of loading of the impact test, where the load is overestimated, due to fiber failures which the model does not take into account very well. This phenomenon is also observed in the case of C2 (Fig. 34), although here the load drop is less, which could be due to another type of fiber failure. And indeed on the impacted side of the $\mathrm{C} 2$ plate, a large crack of about $50 \mathrm{~mm}$ in the $0^{\circ}$ direction is observed (Fig. 35), unlike the D2 plate where no crack is observed on impact side.

This crack of the top $90^{\circ}$ ply could be due to bending of the plate during impact, which induces compression stresses at the top of the laminate. Moreover this plate is particularly sensitive to compression in the top of the laminate, because the $90^{\circ}$ ply is in the short edge of the frame.

These problems of fiber failure modeling may also induce discrepancies in permanent indentation modeling (Fig. 33). Indeed the comparison between experimental and numerical results of permanent indentation shows some inaccurate estimates, in particular for E1 and E2 plates, although the general correlations are accurate. Nevertheless it is difficult to explain and to improve the permanent indentation model if fiber failure modeling problems are not solved and impact damage is not simulated accurately enough. 
Fig. 35 Fiber failure in the case of $\mathrm{C} 2$ observed on $\left[90_{2}, 0_{2},-45_{2}, 45_{2}\right]_{s}$ impacted side

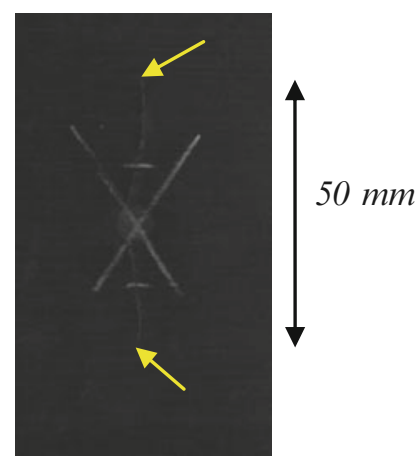

C2-25 J

In conclusion, the modification of the draping sequence enabled us to confirm that the model is able to qualitatively simulate the formation of impact damage, but that other failure phenomena, such as fiber failure under shear or compression [38, 40-42], should be better taken into account. Nevertheless, the model seems to correlate well with experimental results, such as delamination or force-displacement curves, before significant fiber failures. These tests also enabled us to show that permanent indentation simulation needs to be improved, although the problems of fiber failure could be partially responsible for this discrepancy.

\subsection{Effect of Impact Velocity}

Subsequently, the effect of impact velocity was studied to evaluate the reliability of the model, as well as to attempt to separate inertial effects from material strain rate effects on impact damage. In this model, only inertial effects are taken into account and all material parameters are strain rate independent. The inertial effects of an impact test are schematically illustrated in Fig. 36 of Olsson's study [54]. Impact with low velocity and large mass presents quasi-static response, since impact with high velocity and small mass presents a local response controlled by wave propagation. And at the same time, the strain rate effect generally shows an increase in the material parameters with the strain rate [55] (Fig. 37) which induces generally less impact damage.

In Fig. 38, delamination and force-displacement curves are presented for $25 \mathrm{~J}$ impact at $0.5,5$ and $50 \mathrm{~m} / \mathrm{s}$. In order to facilitate the discussion, the $0.5 \mathrm{~m} / \mathrm{s} \mathrm{impact}$ is called the static test, the $5 \mathrm{~m} / \mathrm{s}$ impact is called the reference test, and the $50 \mathrm{~m} / \mathrm{s}$ impact is called the high velocity test.

The difference between the static and reference impacts is very small, in particular for delamination. Nevertheless, oscillations of the force signal are conventionally 

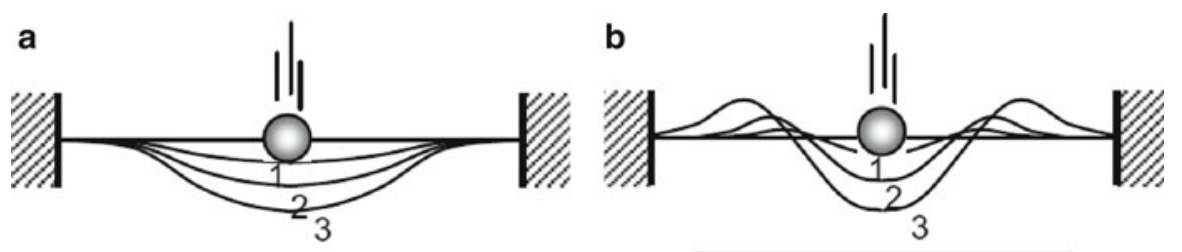

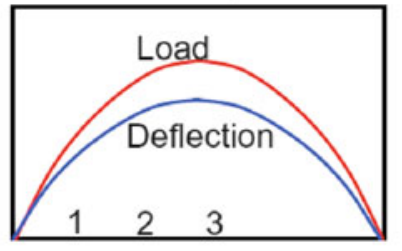

Time

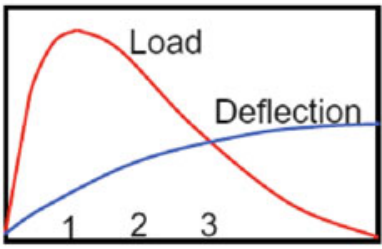

Time

Fig. 36 Comparison of impacts with (a) large mass and low velocity and (b) small mass and high velocity [54]

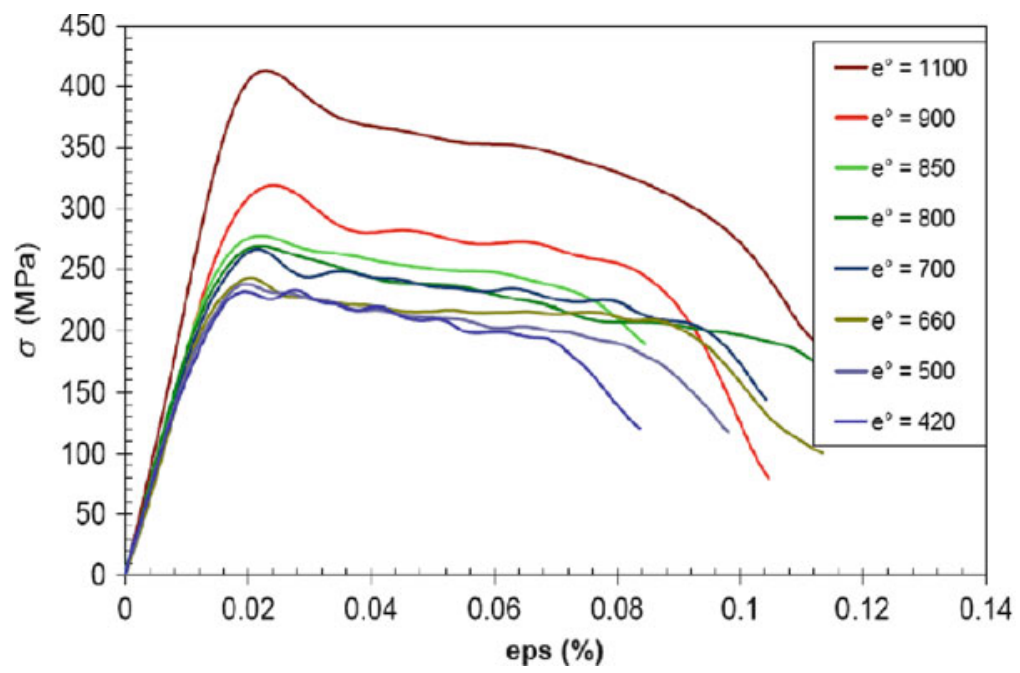

Fig. 37 Effect of strain rate on a compression of T800S/M21 $[ \pm 45]_{3 S}$ laminate [55]

observed in the reference impact, but not in the static case. The range of oscillations seems small enough to have a negligible effect on damage formation. This conclusion is coherent with certain articles in the literature [1,56-58] where impact tests at velocities between 1 and $10 \mathrm{~m} / \mathrm{s}$ are assumed to be equivalent to the static test (Fig. 39).

But this equivalence between static and impact tests, is not relevant for velocity greater than about $10 \mathrm{~m} / \mathrm{s}$, although this threshold is artificial and may depend on material, draping sequence, boundary conditions or impactor mass. With this model, impact damage simulated at high velocity is different and shows a more circular 


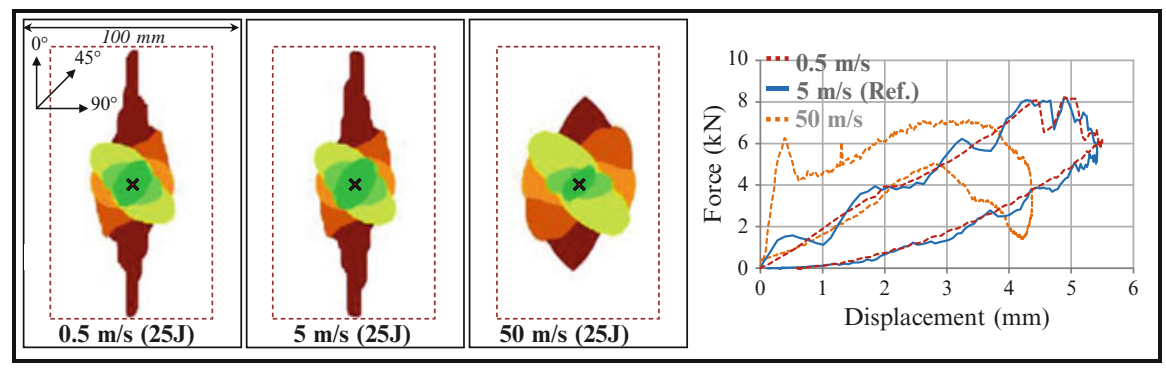

Fig. 38 Simulated effect of impact velocity

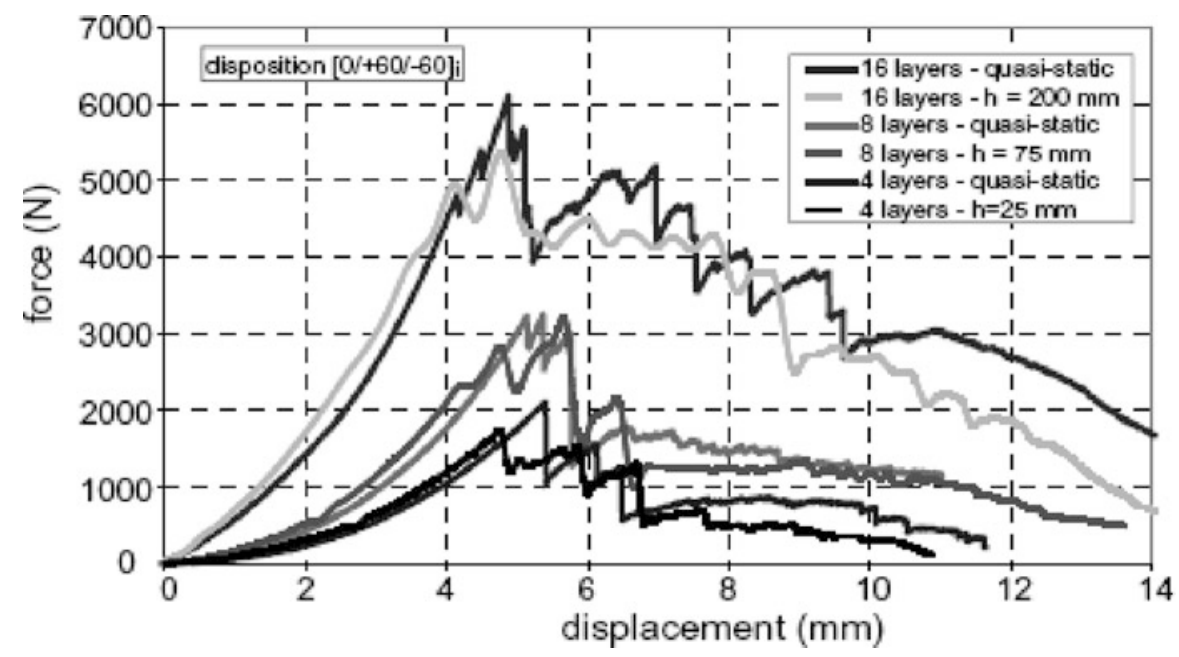

Fig. 39 Comparison between static and dynamic tests performed by Belingardi and Vadori [57]

shape, which is typical of high velocity impact damage, which decreases boundary condition effects compared to inertial effects (Fig. 36). Influence of impact velocity is also illustrated on the force-displacement curve (Fig. 38) where inertial effects are clearly visible for high velocity impacts. This high velocity curve shows that the first load peak at about $0.4 \mathrm{~mm}$-displacement is conventionally due to the inertial effect and does not induce significant damage. Indeed, only some matrix cracks are observed in the impactor contact zone.

Finally experiments were performed at different impact velocities and compared to simulated results (Fig. 40):

- The quasi-static case is an indentation test performed on an electro-mechanical machine at about $10-4 \mathrm{~m} / \mathrm{s}$. This test is driven with imposed velocity up to a maximum displacement of about $5 \mathrm{~mm}$, similar to the $25 \mathrm{~J}$-impact test. This induces impact energy of about $23 \mathrm{~J}$. This energy is imposed for the simulation and a small impact velocity of about $0.5 \mathrm{~mm} / \mathrm{s}$ is chosen in order to avoid an 


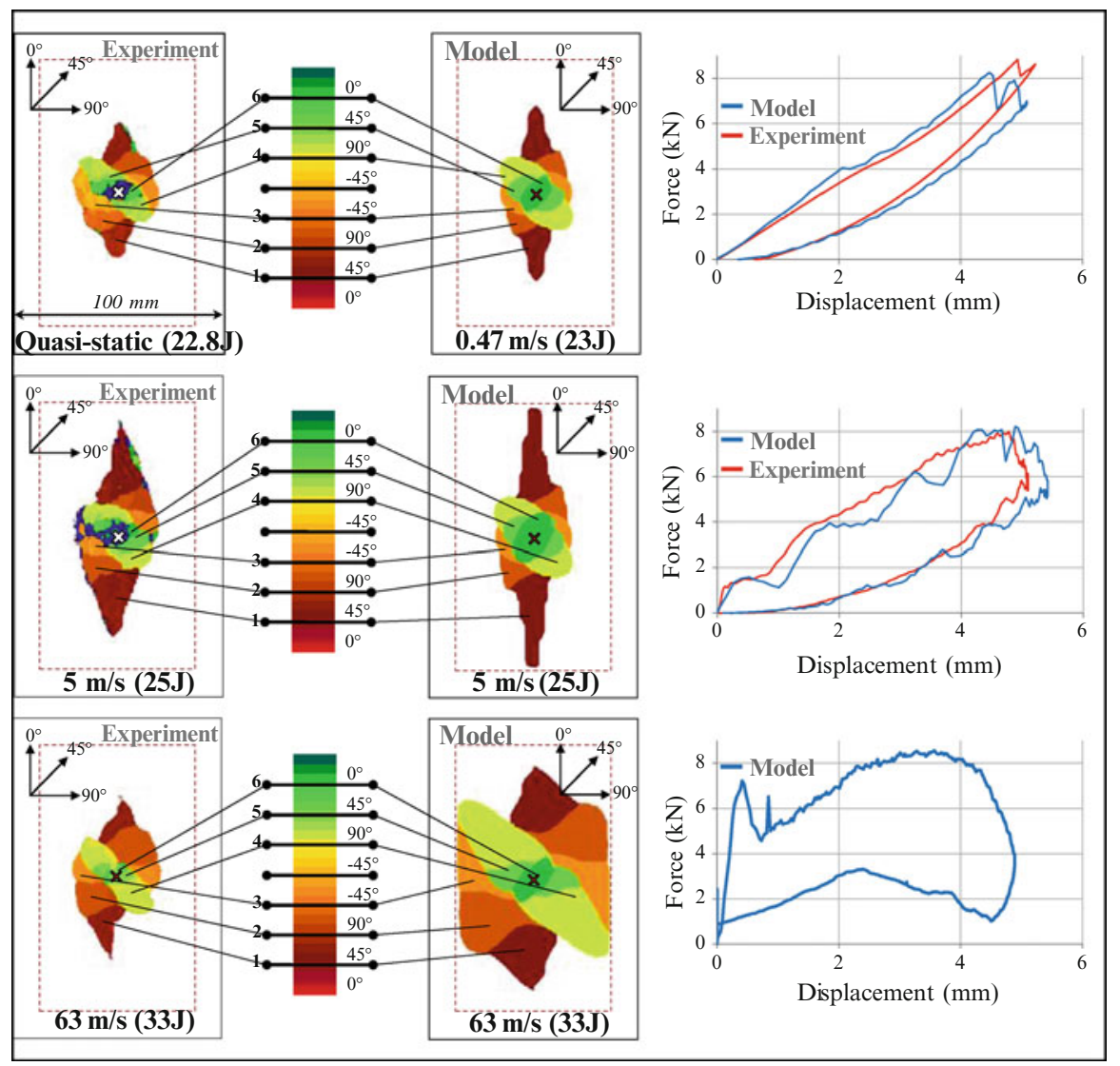

Fig. 40 Experimental and simulated effect of impact velocity and force-displacement curves

overly time-consuming calculation. Of course it has been verified that such a decrease in imposed velocity did not affect significantly the numerical result. A good correlation has observed between the experiment and the model, for delamination and force-displacement. The simulated load drop at about $4.5 \mathrm{~mm}$ displacement is due to fiber failure under tension in plies of the lower half-plate.

- The $5 \mathrm{~m} / \mathrm{s}$-impact test is the reference impact test mentioned above. The satisfactory correlation between the experiment and the model has previously been discussed extensively.

- The $63 \mathrm{~m} / \mathrm{s}$ experimental impact test used a gas gun, with the same boundary conditions and a steel ball of $16 \mathrm{~mm}$-diameter and $34 \mathrm{~g}$-mass. Unfortunately this experimental set up does not allow for precise control of the impact velocity and explains the difference between the required $50 \mathrm{~m} / \mathrm{s}$-velocity and the experimental velocity. Nevertheless a high speed camera is used to measure this velocity. Moreover this type of experimental set up does not allow for force 
signal measurement during impact. Then only the force-displacement curve is represented on the other hand simulated and experimentally obtained delaminated interfaces are represented (Fig. 40). The correlation between experimental and numerical delamination shows that the delamination shapes are accurately simulated, but delaminated areas are overestimated. Once again, the model overestimates the delamination propagation at the end of impact test loading; experimentally obtained delamination data at $63 \mathrm{~m} / \mathrm{s}$ compare favorably with delamination simulated at $50 \mathrm{~m} / \mathrm{s}$ (Fig. 38). Again, as mentioned previously, delamination overestimation could be due to fiber failure which this model does not accurately take into account. Nevertheless, the lack of experimental forcedisplacement data does not support this conclusion, and the evolution of material parameters, such as delamination energy release rate or fiber failure strain, with the strain rate, should be taken into account.

To conclude, modification of impact velocity did not enable us to separate inertial effects from material strain rate effects, and the model needs to be improved to correctly simulate the effect of impact velocity and to be able to answer this question. Other high velocity experimental studies are also necessary to determine whether fiber failure is not accurately estimated. Nevertheless the equivalence between static and low velocity impact tests has been confirmed with this type of boundary conditions. Further studies are needed to validate this equivalence with other boundary conditions, in particular with less stiff boundary conditions.

\subsection{Conclusion of Impact Conditions}

The simulation of different experimental impact tests enabled us to demonstrate the domain validity of the model and to highlight certain effects of the impact conditions.

The study of the effect of impact energy made it possible to set up the damage scenario during impact and to show the fiber failure effect on permanent indentation. The modification of the boundary conditions and stacking sequence showed the importance of other types of fiber failure, such as shearing or compression, on damage creation. Finally the study of the effect of impact velocity failed to separate the inertial effects from the strain rate effects.

\section{Conclusion}

The goal of this work was to stimulate a "test-calculation dialogue" on the composite impact test. Therefore, it has been necessary to simultaneously carry out a refined experimental study of the different types of impact damage, and to build a numerical model able to simulate these observations. The accurate correlation of the model 
with this refined experimental database enabled us to have relative confidence in this model, despite a few non-standard material parameters. Indeed the bibliography shows a general lack of detailed validation of impact modeling and the originality of this work is to use refined and complementary experimental data to build and validate a numerical model.

This approach enabled us to define an accurate model for impact, with some original points in modeling:

- An original scenario of permanent indentation with a phenomenon of debris blocking in the matrix cracks and the corresponding model were proposed. Cohesive interface elements of matrix cracking were used with a "plastic-like" behavior to simulate this phenomenon.

- A particular modeling of fiber failure was set up with original formulation between the integration points of the volume element in order to reproduce a constant energy release rate per unit area. The use of the strains extrapolated at nodes also to better account for the bending behavior of plies with only one element in the ply thickness.

- The model was then used for in-depth analysis of impact tests, which cannot be done directly from the experiments alone:

- Calculations were performed to evaluate the distribution of the dissipated energy between the different damage types. For the reference impact case, the dissipated energy is divided into two equal parts, the first related to delamination and the second related to fiber failure.

- The modeling of impacts at different energy levels enabled us to set up the damage scenario during impact. In particular the strong effect of fiber failure on the permanent indentation was demonstrated.

Finally, different configurations of impact were simulated to explore the validity domain and limitations of the model:

- The modeling of impacts with different stacking sequences showed the importance of fiber failure, under shear or compression solicitations - which are not yet taken into account in the model - on the impact damage morphology.

Finally significant work is still necessary to accurately simulate all the impact tests shown in this article, although this seems feasible. Moreover the impact model is only a first step, and the residual strength of the structure should also be numerically determined, in order to totally design a composite structure with impact damage tolerance and to optimize it. In addition, this type of model represents composite damage, observed in other kinds of loading, and could be used to simulate other dimensioning cases, such as pull-through [59], bearing of bolted composites or crashes. 


\section{References}

1. Abrate S (1998) Impact on composite structures. Cambridge University Press, Cambridge

2. Petit S, Bouvet C, Bergerot A, Barrau JJ (2007) Impact and compression after impact experimental study of a composite laminate with a cork thermal shield. Compos Sci Technol 67:3286-3299

3. Zheng D, Binienda WK (2007) Effect of permanent indentation on the delamination threshold for small mass impact on plates. Int J Sol Struct 44(25-26):8143-8158

4. Eve O (1999) Etude du comportement des structures composites endommagées par un impact basse vitesse. Thèse de doctorat, Université de Metz

5. Allix O, Blanchard L (2006) Mesomodeling of delamination: towards industrial applications. Compos Sci Technol 66:731-744

6. Choi HY, Chang K (1992) A model for predicting damage in graphite/expoxy laminated composites resulting from low-velocity point impact. J Comp Mat 26(14):2134-2169

7. De Moura MF, Gonçalves SF (2004) Modelling the interaction between matrix cracking and delamination in carbon-epoxy laminates under low velocity impact. Compos Sci Technol 64:1021-1027

8. Guinard S, Allix O, Guédra-Degeorges D, Vinet A (2002) A 3D damage analysis of lowvelocity impacts on laminated composites. Compos Sci Technol 62:585-589

9. Mulle M, Zitoune R, Collombet F, Robert L, Grunevald YH (2009) Embedded FBGs and 3 -D DIC for the stress analysis of a structural specimen subjected to bending. Compos Struct 91:48-55

10. Rouchon J (1995) The fatigue and damage tolerance aspects for composite aircraft structures. Proceedings of ICAF symposium, Delft, The Netherlands

11. Alderliesten RC (2008) Damage tolerance of bonded aircraft structures. Int J Fati 31(6):1024 1030

12. Tropis A, Thomas M, Bounie JL, Lafon P (1994) Certification of the composite outer wing of the ATR72. J Aero Eng 209:327-339

13. Chang FK, Chang K (1987) A progressive damage model for laminate composites containing stress concentrations. J Comp Mat 834-855

14. Aymerich F (2008) Priolo, "Characterization of fracture modes in stiched and unstiched crossply laminates subjected to low-velocity impact and compression after impact loading”. Int J Imp Eng 35:591-608

15. Renault M (1994) Compression après impact d'une plaque stratifiée carbone époxyde - Etude expérimentale et modélisation éléments finis associée. Rapport interne EADS CCR

16. Lopes CS, Camanho PP, Gürdal Z, Maimí P, González EV (2009) Low-velocity impact damage on dispersed stacking sequence laminates. Part II: Numerical simulations. Compos Sci Technol 69(7-8):937-947

17. Faggiani A, Falzon BG (2010) Predicting low-velocity impact damage on a stiffened composite panel. Compos Part A 41(6):737-749

18. Geubelle PH, Jeffrey S (1998) Baylor Impact-induced delamination of composites: a 2D simulation. Compos Part B Eng 29(5):589-602

19. Aymerich F, Dore F, Priolo P (2009) Simulation of multiple delaminations in impacted crossply laminates using a finite element model based on cohesive interface elements. Compos Sci Technol 69:1699-1709

20. Wisnom MR (2010) "Modelling discrete failures in composites with interface elements" Comp. Compos Part A Appl Sci Manufac 41(7):795-805

21. Davies GAO, Olsson R (2004) Impact on composite structures. Aero J 108:541-563

22. Aoki Y, Suemasu H, Ishikawa T (2007) Damage propagation in CFRP laminates subjected to low velocity impact and static indentation. Adv Mater 16(1):45-61

23. Borg R, Nilsson L, Simonsson K (2004) Simulation of low velocity impact on fiber laminates using a cohesive zone based delamination model. Compos Sci Technol 64:279-288 
24. Ladeveze P, Lubineau G, Marsal D (2006) Towards a bridge between the micro- and mesomechanics of delamination for laminated composites. Compos Sci Technol 66:698-712

25. Zhang Y, Zhu P, Lai X (2006) Finite element analysis of low-velocity impact damage in composite laminated plates. Mater Des 27:513-519

26. Lammerant L, Verpoest I (1996) Modelling of the interaction between matrix cracks and delaminations during impact of composite plates. Compos Sci Technol 56:1171-1178

27. Tita V, Carvalho J, Vandepitte D (2008) Failure analysis of low velocity impact on thin composite laminates: experimental and numerical approaches. Compos Struct 83:413-428

28. Johnson HE, Louca LA, Mouring S, Fallah AS (2009) Modelling impact damage in marine composite panels. Int J Imp Eng 36:25-39

29. Iannucci L, Willows ML (2006) An energy based damage mechanics approach to modelling impact onto woven composite materials - part I: numerical models. Compos Part A 37:20412056

30. Iannucci L, Willows ML (2007) An energy based damage mechanics approach to modelling impact onto woven composite materials - part II: experimental and numerical results. Compos Part A 38:540-554

31. Bouvet C, Castanié B, Bizeul M, Barrau JJ (2009) Low velocity impact modeling in laminate composite panels with discrete interface elements. Int J Sol Struct 46(14-15):2809-2821

32. Ha-Minh C, Kanit T, Boussu F, Abdellatif I (2011) Numerical multi-scale modeling for textile woven fabric against ballistic impact. Compos Mater Sci 50(7):2172-2184

33. Mi Y, Crisfield MA, Davies GAO (1998) Progressive delamination using interface elements. J Compos Mater 32(14):1246-1272

34. Prombut P (2007) Caractérisation de la propagation de délaminage des stratifiés composites multidirectionnels. Thèse de doctorat, université de Toulouse

35. Prombut P, Michel L, Lachaud F, Barrau JJ (2006) Delamination of multidirectional composte laminates at $0^{\circ} /$ theta $^{\circ}$ ply interfaces. Eng Fract Mech 7:2427-2442

36. Raimondo L, Iannucci L, Robinson P, Curtis PT (2012) A progressive failure model for meshsize-independent $\mathrm{FE}$ analysis of composite laminates subject to low-velocity impact damage. Comp Sci Technol 72:624-632

37. Hashin Z, Rotem A (1973) A fatigue failure criterion for fiber-reinforced materials. J Compos Mater 7:448-464

38. Hashin Z (1980) Failure criteria for uni-directional fibre composites. J Appl Mech 47:329-334

39. Pinho ST, Robinson P, Iannucci L (2006) Fracture toughness of the tensile and compressive fibre failure modes in laminated composites. Compos Sci Technol 66:2069-2079

40. Bazant ZP, Oh BH (1983) Progressive Carck and band theory for fracture of concrete. Mater Struct 16:155-177

41. Lapczyk I, Hurtado JA (2007) Progressive damage modelling in fiber-reinforced materials. Compos Part A 38:2333-2341

42. Shi Y, Swait T, Soutis C (2012) Modelling damage evolution in composite laminates subjected to low velocity impact. Comp Struct 94(9):2902-2913

43. Yang Q, Cox B (2005) Cohesive models for damage evolution in laminated composites. Int J Fract 133:107-137

44. Pinho ST (2005) Modelling failure of laminated composites using physically-based failure models. PhD of the University of London

45. Guocai W, Jenn-Ming Y, Hahn HT (2007) The impact properties and damage tolerance of bi-directionally reinforced fiber metal laminates. J Mater Sci 42:948-957

46. Wardle BL, Lagace PA (1997) On the use of quasi-static testing to assess impact damage resistance of composite shell structures. J Reinf Plast Compos 16:1093-1110

47. Chen P, Shen Z, Xiong J, Yang S, Fu S, Ye L (2006) Failure mechanisms of laminated composites subjected to static indentation. Compos Struct 75:489-495

48. Nettles AT, Douglas MJ (2002) A comparison of quasi-static indentation testing to low velocity impact testing. ASTM, Composite Materials: testing, design and acceptance criteria 1416: $116-130$ 
49. Chang DC, Khetan RP (1997) Surface damage of steel, aluminium and chopped-fiber composite panels due to projectile impact. J Reinf Plast Compos 3:193-203

50. Caprino G, Langella A, Lopresto A (2003) Indentation and penetration of carbon fibre reinforced plastic laminates. Compos Part B 34:319-325

51. Fiedler B, Hojo M, Ochiai S, Schulte K, Ando M (2001) Failure behavior of an epoxy matrix under different kinds of static loading. Compos Sci Technol 61:1615-1624

52. Abi Abdallah, Bouvet C, Rivallant S, Broll B, Barrau JJ (2009) Experimental analysis of damage creation and permanent indentation on highly oriented plates. Compos Sci Technol 69(7-8): $1238-1245$

53. HexPly M21 product data, Hexcel company, http://www.hexcel.com/Resources/DataSheets/ Prepreg-Data-Sheets/M21_global.pdf

54. Olsson R (2010) Analytical model for delamination growth during small mass impact on plates. Int J Sol Struct 47:2882-2892

55. Ilyas M, Espinosa C, Lachaud F, Salaün M (2011) Modelling aeronautical composite laminates behaviour under impact using a saturation damage and delamination continuous material model. Key Eng Mater 452-3:369-372

56. Curtis J, Hinton MJ, Li S, Reid SR, Soden PD (2000) Damage, deformation and residual burst strength of filament-wound composite tubes subjected to impact or quasi-static indentation. Comp Part B 31:419-433

57. Belingardi G, Vadori R (2003) Influence of the laminate thickness in low velocity impact behavior of composite material plate. Compos Struct 61:27-38

58. Sjoblom PO, Hartnes TJ, Cordell TM (1988) On low velocity impact testing of composite materials. J Compos Mater 22:30-52

59. Adam L, Bouvet C, Castanié B, Daidié A, Bonhomme E (2012) Discrete ply model of circular pull-through test of fasteners in laminates. Comp Struct 94(10):3082-3091 